\title{
Angiodiversity and organotypic functions of sinusoidal endothelial cells
}

\author{
Philipp-Sebastian Koch ${ }^{1,3}$ (D) Ki Hong Lee ${ }^{2,3,4} \cdot$ Sergij Goerdt ${ }^{1,3} \cdot$ Hellmut G. Augustin ${ }^{2,3}$ (D)
}

Received: 15 November 2020 / Accepted: 4 March 2021 / Published online: 21 March 2021

(c) The Author(s) 2021

\begin{abstract}
'Angiodiversity' refers to the structural and functional heterogeneity of endothelial cells (EC) along the segments of the vascular tree and especially within the microvascular beds of different organs. Organotypically differentiated EC ranging from continuous, barrier-forming endothelium to discontinuous, fenestrated endothelium perform organ-specific functions such as the maintenance of the tightly sealed blood-brain barrier or the clearance of macromolecular waste products from the peripheral blood by liver EC-expressed scavenger receptors. The microvascular bed of the liver, composed of discontinuous, fenestrated liver sinusoidal endothelial cells (LSEC), is a prime example of organ-specific angiodiversity. Anatomy and development of LSEC have been extensively studied by electron microscopy as well as linage-tracing experiments. Recent advances in cell isolation and bulk transcriptomics or single-cell RNA sequencing techniques allowed the identification of distinct LSEC molecular programs and have led to the identification of LSEC subpopulations. LSEC execute homeostatic functions such as fine tuning the vascular tone, clearing noxious substances from the circulation, and modulating immunoregulatory mechanisms. In recent years, the identification and functional analysis of LSEC-derived angiocrine signals, which control liver homeostasis and disease pathogenesis in an instructive manner, marks a major change of paradigm in the understanding of liver function in health and disease. This review summarizes recent advances in the understanding of liver vascular angiodiversity and the functional consequences resulting thereof.
\end{abstract}

Keywords Angiodiversity $\cdot$ Endothelial cell heterogeneity $\cdot$ Liver vasculature $\cdot$ Sinusoids $\cdot$ Angiocrine signaling

\section{Introduction}

Vascular functional heterogeneity is an ancient concept dating back to Hippocrates (460-370 B.C.) and Galen (129-205 AD) who already believed that the cardiovascular system consists of two independent networks made of arteries and veins [1]. Beyond the first attempts to understand the blood vascular system as a whole, technical advances in microscopy and cell culture have facilitated the characterization of organ to organ (inter-organ) vascular specification [2, 3]. Recent high-resolution studies on organotypic vasculatures have shed insight into the molecular repertoires of different vascular beds. Microarray analyses enabled to decipher organotypically differentiated endothelial cells (EC) identifying differentially expressed transcription factors (TFs) and angiocrine (i.e., EC-derived) signatures regulating organotypic vascular heterogeneity [4]. Yet, the analysis of the intra-organotypic vascular heterogeneity remained elusive, mainly due to technical limitations. Recent advances in single-cell technology have eventually allowed to generate

4 Faculty of Biosciences, Heidelberg University, 69120 Heidelberg, Germany 
high-resolution epigenomic, transcriptomic, and proteomic maps of blood vessels within different organs. Concurrently, these data help to elucidate novel and distinct molecular markers for both inter- and intra-organ specialization and heterogeneity of differentiated EC [5]. It is increasingly recognized that inter- and intra-organotypically differentiated EC have unique molecular programs and mechanisms to exert highly specialized functions, adapted to the needs of the respective vascular bed within the different organs. Therefore, the organotypic vasculature is no longer perceived as a simple passive conduit to deliver blood. Instead, organotypic EC are now widely recognized as active gatekeeper of their immediate tissue microenvironment capable of secreting EC-derived paracrine-acting cytokines, socalled 'angiocrine' factors [6].

This review summarizes the current knowledge of organotypic vascular differentiation focusing on the liver, which has in recent years emerged as prototypic example of organ-specific angiodiversity. The microvasculature of the liver is composed of liver sinusoidal endothelial cells (LSEC) that line the liver sinusoids. LSEC have unique morphological features and are functionally highly specialized. They extend from the portal area and carry blood along the sinus to eventually drain through the central vein into the inferior cava vein, thereby generating physical gradients of oxygen, shear stress, and redox along the axis of the liver lobule. LSEC are specialized according to their location in the sinusoid and categorized into periportal, midlobular, and centrilobular subtype [7]. Recent single-cell RNA sequencing analyses could deconvolute this spatial zonation of LSEC along the axis of the liver lobule in substantial molecular detail $[8,9]$. Moreover, demarcated markers for LSEC and hepatocytes from different metabolic zones could be identified in both human and murine liver, allowing to spatially decipher the crosstalk between these cells which indicates functional diversity of LSEC subtypes [8-10]. For example, pericentral LSEC, located adjacent to the central vein, are the main source of the Wnt ligands Wnt2 and Wnt9b as well as the Wnt-signaling enhancer Rspo3. These angiocrine Wnt factors are indispensable in establishing a unique niche, which fuels Wnt-addicted self-renewing Axin2- and Lgr5-positive hepatocytes. Loss of angiocrine Wnt signatures consequently leads to the loss of the central hepatocyte signatures with subsequent perturbation of liver size, liver zonation, and impaired regenerative capacity of the liver [11-16].

Midlobular LSEC represent the major EC subpopulation of the sinusoids. They display lymphatic-like properties expressing scavenger receptors such as CD206, STAB1, STAB2, LYVE-1, and VEGFR3. Indeed, midlobular LSEC serve as scavenger and antigen-presenting cells facilitating the clearance of a variety of factors, immune complexes, viruses, and lipopolysaccharides from the circulation [6].
Moreover, angiocrine Bone morphogenetic protein (BMP)2and BMP6 signaling by midlobular LSEC controls local and systemic iron metabolism [17, 18].

Periportal LSEC display 'tip cell'-like features due to the expression of Dll4 and Esml. They thereby create a unique niche for resident LSEC progenitor cells. A recent publication reported CD157-positive resident endothelial progenitor cells residing adjacent to the portal vein that can undergo proliferative expansion following acute liver damage [19]. Embryonically, portal EC serve as niche for hematopoietic progenitor cells during fetal liver hematopoiesis [20]. Furthermore, Notch signaling in portal EC orchestrates monocyte recruitment and differentiation of Kupffer cells $(\mathrm{KC})$, which are liver-resident macrophages. Depletion of $\mathrm{KC}$ results in LSEC and hepatic stellate cell (HSC; liverspecific pericytes) activation, which reprogram to orchestrate monocyte recruitment and further instigate the differentiation of recruited monocytes via Notch-BMP signaling [21]. Moreover, a so-called "immune zonation" along the sinusoids, created by periportal localization of myeloid and lymphoid resident immune cells, was found to result from gut microbiota-induced MYD88-dependent signaling in LSEC to limit inflammatory responses in periportal areas while protecting the pericentral niche [22].

Specialized LSEC are not just involved in maintaining liver homeostasis. They also play pivotal roles in liver regeneration and adaptation to pathological challenge. The loss of organ-specific LSEC differentiation, called sinusoidal capillarization, not only changes LSEC morphology with the loss of fenestrations and synthesis of pro-fibrotic molecules, such as basement membrane collagen IV or laminins [23]. More importantly, it impairs a fundamental LSEC function, namely the capacity to maintain the quiescence of HSC. In the healthy liver, HSCs, which represent the liver cells with the most fibrogenic potential, are quiescent, non-proliferative and store vitamin A (retinol). Upon activation, they switch to a proliferative and inflammatory phenotype producing excess extracellular matrix (ECM) molecules [24]. Sinusoidal capillarization, thereby, represents an essential step in the development of fibrotic liver disease. Acute injury is compensated by the capability of the liver to regenerate, but when liver injury becomes chronic (e.g., in non-alcoholic steatohepatitis (NASH), viral hepatitis, alcoholic liver disease, and autoimmune disorders of the liver), liver fibrosis with excessive deposition of ECM is unavoidable. In all of these settings, LSEC are the first liver cell population to be exposed to toxic stimuli. It is, therefore, not surprising that LSEC dysfunction precedes liver fibrosis [25]. Hence, restoration of LSEC differentiation critically contributes to maintaining HSC quiescence and promotes resolution of liver fibrosis [26].

We will during the first part of this review discuss the unique morphological characteristics of LSEC as well as 
the molecular drivers and origin of LSEC angiodiversity. The second part will be devoted to the highly specialized functions of LSEC controlling liver homeostasis, regeneration, and disease.

\section{Angiodiversity of liver sinusoidal endothelial cells (LSEC)}

\section{Anatomical traits of sinusoidal endothelial cells}

The liver vasculature is anatomically and physiologically unique compared to other organs, as the liver has a dual blood supply receiving both, oxygen-rich blood from the hepatic artery (30\%) and blood rich in nutrients from the portal vein $(70 \%)$. After merging, the blood flow continues along the liver sinusoids which are lined by LSEC (Fig. 1). LSEC account for approximately $15-20 \%$ of total liver cells and $3 \%$ of the total liver mass $[6,27]$. They form a discontinuous fenestrated EC layer that is morphologically different from most other EC types due to their unique structure lacking a continuous basement membrane and a diaphragm but instead contain open pores within the EC layer that are called fenestrae [28]. The sinusoidal vasculature enables free transfer of fluid, ions, nutrients, small and large solutes, as well as metabolites to the space of Disse and is thereby in direct contact with the parenchymal liver cells (hepatocytes) and non-parenchymal cells such as HSC (Fig. 1). Beyond the liver, sinusoidal EC are also found in the spleen, the bone marrow, the adrenal medulla, and the pituitary gland [6]. Among these, LSEC remain the best studied type of discontinuous fenestrated EC.

LSEC fenestrae with a diameter of 50-150 $\mathrm{nm}$ are grouped in clusters that form a sieve plate. They are highly plastic and dynamic. Intracellular microfilaments, intermediate filaments, and microtubules enable the dynamic adaptation to

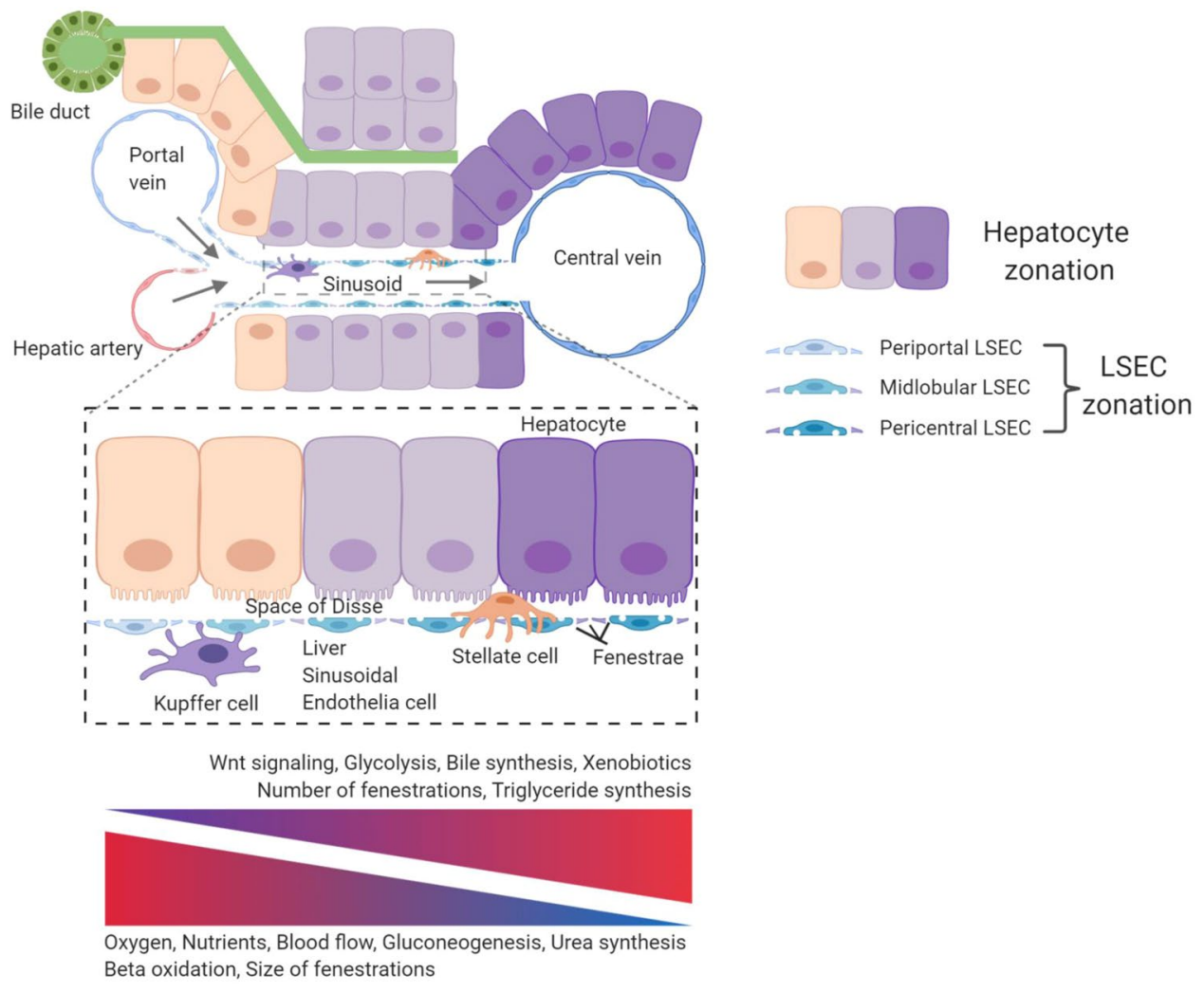

Fig. 1 Angiodiversity of the hepatic endothelium. Nutrient-rich blood from the gastrointestinal tract enters the sinusoid via the portal vein and mixes with oxygen-rich blood from the hepatic artery. The blood then moves through the fenestrated sinusoidal vasculature and exits the liver via the central vein creating an oxygen and blood flow gradient along the axis of the liver lobule. These physical gradients establish a "zonation" of hepatocytes and LSEC. Hepatocytes adjacent to the portal vein show high gluconeogenesis, urea synthesis, and beta oxidation activity. In turn, pericentral hepatocytes are characterized with increased glycolysis, bile synthesis, xenobiotics metabolism, and triglyceride synthesis. Fenestrations of LSEC are larger in the periportal area, whereas they are more abundant in pericentral regions. Pericentral LSEC modulate the spatial division of hepatocytes by secreting angiocrine Wnt ligands and Wnt-signaling enhancer Rspo3. The hepatic microenvironment is mainly determined by the interplay of the four major cell populations, namely hepatocytes, LSEC, HSC, and $\mathrm{KC}$. While $\mathrm{KC}$ are located in the sinusoids, HSC reside in the space of Disse, which is a perisinusoidal space between LSEC and hepatocytes 
changing microenvironmental milieus [29, 30]. Periportal and pericentral LSEC exhibit varying degrees of fenestration. Periportal LSEC have lower porosity of fenestrae (larger in size, but fewer in number) compared to pericentral LSEC that contain smaller size fenestrations but are more abundant in number [7, 30]. Likewise, high-resolution analysis revealed the dynamic nature of opening and closing sinusoidal fenestrations in response to varying stimuli [31].

\section{Development of liver sinusoidal endothelial cells and their self-renewal}

Developmentally, LSEC develop from continuous EC. In the human embryo, the phenotypic switch from the continuous to the sinusoidal EC phenotype occurs between 5 and 12 weeks of gestation and is characterized by the loss of continuous EC markers and a reduction of perisinusoidal laminin deposition. Functional LSEC specification is completed around 20 weeks of gestation [32]. Murine LSEC precursors (angioblasts) can first be detected around embryonic day (E)9.0, and the first nascent sinusoids are detected between E9.5 and E10.5 [33] (Fig. 2a).Yet, the transcriptional signatures of sinusoidal EC can be captured as early as E8.75 [34]. Following colonization of the liver by yolk sac-derived stem cells, expansion of hematopoietic stem and progenitor cells (HSPC) starts in the fetal liver around this time of development [35]. The proper switch from continuous to sinusoidal EC specification is critical already during these early stages of embryonic development. Notably, genetic inactivation of the transcription factor Gata4 in liver EC causes defects in sinusoidal EC specification around E10.5-E11.5. This results in liver hypoplasia, fibrosis, and impaired colonization of HSPC into the fetal liver, leading to anemia and embryonic lethality [36]. These findings have unambiguously

(a)

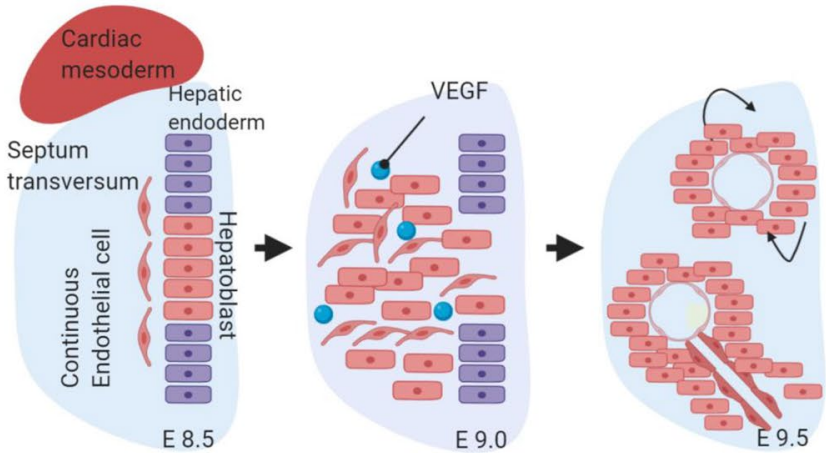

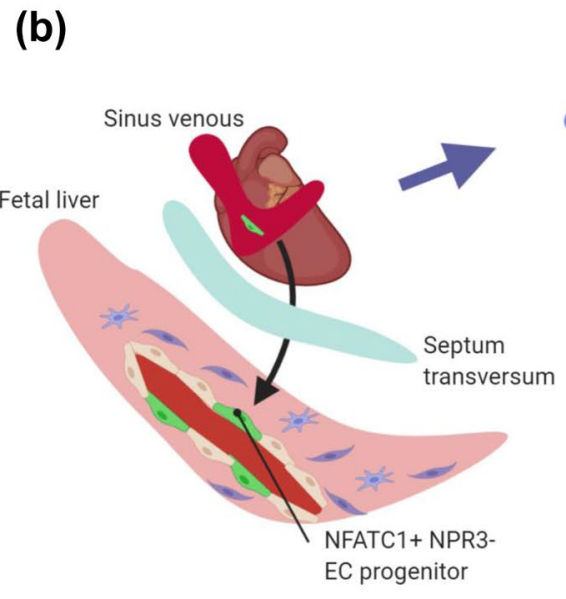

Fig. 2 Development of liver sinusoidal endothelial cells. Multiple source may give rise to liver EC, but a unifying concept of LSEC specification is still missing. a Genetic in vivo studies have shown that hepatoblasts in the septum transversum mesenchyme coordinate LSEC development through the VEGF signaling pathway. b Recent

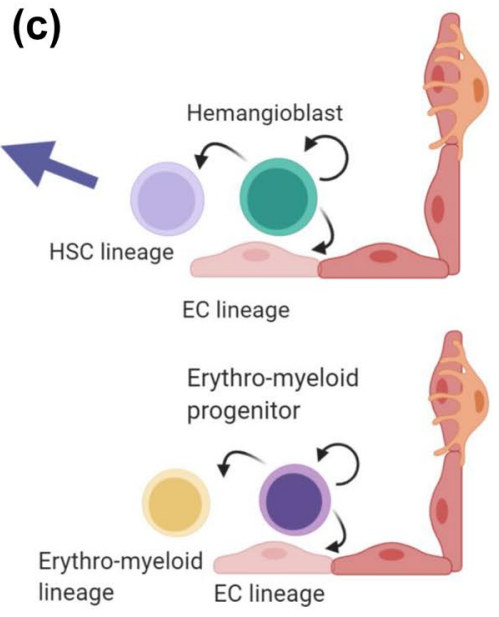

fate mapping studies have indicated a pivotal role of cardiac endothelial progenitor cells in establishing the liver vasculature. Sinus venous-derived NFATC1+ and NPR3- endothelial progenitors may contribute to liver endothelium. c LSEC may also be derived from hemangioblasts and/or erythro-myeloid progenitors 
established the critical role of hepatic microvascular specification for fetal hematopoiesis and liver development.

These genetic experiments have shown that vascular and organ development are tightly coupled. Indeed, following hepatic specification and liver diverticulum formation, hepatoblast-derived VEGF drives angioblast specification, whereas in turn, differentiating EC are critical for hepatic development prior to forming functioning blood vessels (Fig. 2a). Correspondingly, loss of EC in Flkl/Kdr (Vegfr2) mutant embryos resulted in defective liver morphogenesis, as cells from the hepatic endoderm could not populate the septum transversum mesenchyme, indicating a critical role of cell-cell interactions between the EC and the hepatic endoderm during liver development [33]. Vice versa, hepatoblasts induce LSEC specification in a paracrine manner via both, direct interaction and VEGF signaling [32, 33, 37]. Similarly, autocrine/paracrine-acting Notch and transforming growth factor $\beta$ (TGF- $\beta$ ) pathway signaling play pivotal roles during LSEC development [34].

Recent lineage-tracing studies on LSEC development have shown that NFATC $1^{+}$and NPR3- progenitor cells from the sinus venous endocardium serve as a relevant source of the liver vasculature including LSEC [38] (Fig. 2b). Interestingly, while $\mathrm{EC}$ are generally considered to be derived from mesodermal progenitor cells, FOXA2-positive hepatic endoderm cells have also been proposed to give rise to a subset of liver EC [39], suggesting that LSEC can potentially originate from both, mesenchymal and endodermal progenitor populations and even partially share a common progeny with cardiac EC [38, 39]. In zebrafish, the liver vasculature has also been reported to be derived from angioblasts residing in the posterior cardinal vein without arterial contribution [40]. Together, these lineage-tracing experiments indicate different sources for liver EC with LSEC originating from venous derivates [38-40].

There is also evidence suggesting that EC may be derived from hemangioblasts, which represent a common progenitor of the endothelial and the hematopoietic lineages [41, 42] (Fig. 2c). Subsequently, the divergence of sinusoidal and vascular EC from the common EC progenitor occurs around E9.5 [34]. A mouse single-cell molecular map during gastrulation and mesoderm diversification validated the origin of the hematoendothelial lineages with the expression of Flkl/ $K d r$ and Tall as molecular switch determining lineage fate to either EC or hematopoietic cells during mesoderm diversification [43, 44]. Hematopoietic cells then further develop and are maintained by the niches within the developing liver, typically by EC and HSC through paracrine-acting stem cell factor [45]. Temporally restricted lineage-tracing experiment of $C d h 5$-expressing cells demonstrated the contribution of common progenitor cells to the liver vasculature [46]. In parallel, myeloid lineage progenitor cells contribute to the liver vasculature during proliferation [47, 48]. Specifically, lineage-tracing experiments with CSF1R, a specific marker for the myeloid lineage, showed incorporation of Csflrderived LSEC in the liver vasculature demonstrating that LSEC may also be derived from erythro-myeloid linage progenitors (EMP) [48] (Fig. 2c). Yet, this hypothesis was recently challenged as no contribution of EMP cells to the vasculature was demonstrated in independently performed inducible lineage-tracing experiments [49].

Substantial effort has been made to decipher the molecular mechanisms of LSEC differentiation from embryonic (ESC) and pluripotent stem cells (PSC). KDR-positive hepatic progenitor cells may emerge from KDR-negative human ESC in hepatic differentiation medium. These differentiated KDR-positive cells then contribute to the liver EC lineage [50]. Using a murine ESC model, EC derived from ESC have been shown to phenocopy LSEC features when exposed to adrenomedullin and upon inhibition of TGF- $\beta$ signaling $[51,52]$. These findings were also validated in human-induced pluripotent stem cells (iPSC), in which the inhibition of TGF- $\beta$ in iPSC-derived EC led to a switch to LSEC-like cells [53]. Interestingly both, hPSC-derived arterial and venous angioblasts are capable to differentiate into LSEC-like cells that upregulate LSEC markers and behave functionally as LSEC. Yet, upon balancing cyclic AMP, hypoxia, and inhibition of TGF- $\beta$ signaling, angioblasts from venous origin upregulate LSEC markers more robustly than angioblasts with arterial pre-differentiation. These hPSC-derived LSEC could be transplanted and exhibited functional LSEC competence [54]. These findings will guide future research aimed at exploring opportunities to $e x$ vivo generate and expand functional LSEC for regenerative medicine purposes.

LSEC plasticity during liver damage depends on the fitness of the resident vasculature. Using definite fate mapping techniques, a recent study has shown that liver neoangiogenesis is mediated by the expansion of resident LSEC upon different pathological challenges [55]. Resident LSEC progenitors residing adjacent to the portal vein have been characterized as CD157-positive, self-renewable, ABC transporter expressing cells with stem cell-like features. Upon lineage-tracing, transplantation, and regeneration experiments, CD157-positive cells regenerate the liver vasculature [19] (Fig. 3). Yet, resident LSEC progenitor cells may not be the sole source of the regenerating LSEC vasculature. Bone marrow (BM)-derived progenitor cells have also been proposed to contribute to LSEC regeneration [56, 57] (Fig. 3). Importantly though, bone marrow transplantation in such fate mapping experiments mostly requires radiation, which in itself may lead to massive damage of LSEC. Fate mapping without radiation, e.g., in parabiosis experiments could solidly exclude the contribution of BM-derived progenitor cells towards vascularization during liver regeneration in a partial hepatectomy model [55]. 


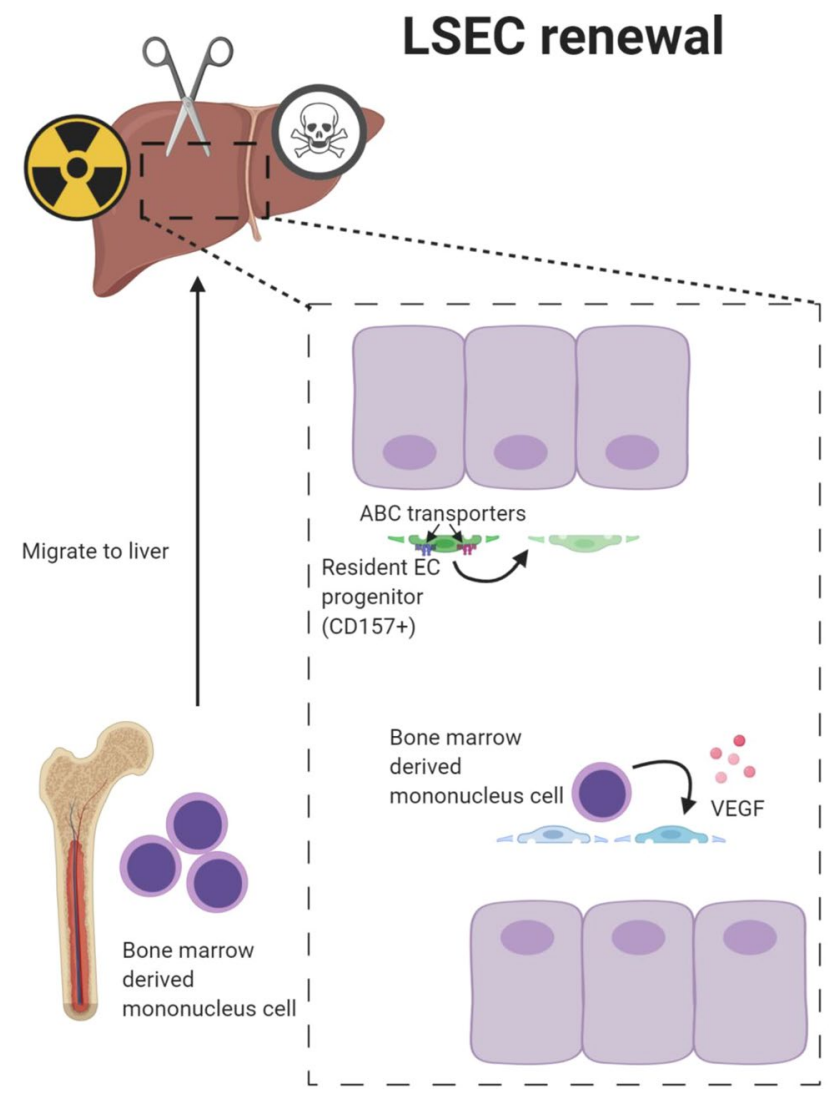

Fig. 3 Self-renewal of liver sinusoidal endothelial cells. LSEC are highly plastic and can self-renew upon different challenges. Resident LSEC progenitors have a unique molecular signature expressing CD157 and ABC transporters. CD157-positive LSEC are self-renewable and can replenish the liver microvasculature following challenge. In addition to resident LSEC progenitors, BM-derived progenitor cells may be recruited to the liver and contribute to the regenerating liver vasculature following severe, resident EC damaging challenge such as irradiation-induced vascular injury.

\section{Transcription factors regulating LSEC differentiation}

Microarray analyses of the organotypic sinusoidal vasculatures of the bone marrow and the liver, and to a lesser extent also the spleen, revealed high levels of the Ets TF family member Sfpil [4]. In contrast, sinusoidal Tbx3 expression was found reduced compared to other vascular beds. Comprehensive gene expression analysis, comparing freshly isolated LSEC with cultured LSEC and rat lung microvascular EC, identified Gata4 in a cluster of transcriptional regulators (Gata4, Lmo3, Tfec, Maf) as one of the critical TF for LSEC differentiation [58]. Indeed, GATA4 is essential for fetal LSEC specification acting as a counter regulator of continuous EC gene expression and inducer of LSEC-specific genes. LSEC-restricted deletion of Gata4 using Stab2-iCre as Cre driver for early embryonic excision resulted in transdifferentiation of sinusoidal EC $\left(\mathrm{STAB} 2^{+}, \mathrm{LYVE}-1^{+}, \mathrm{CD} 31^{\mathrm{lo}}\right)$ to acquire traits of continuous capillaries $\left(\mathrm{CD} 31^{+}, \mathrm{EMCN}^{+}\right.$,
$\mathrm{CAV}^{+}$) with ectopic basement membrane deposition and increased VE-cadherin expression. This transdifferentiation did not only cause liver hypoplasia and increased ECM deposition, but also impaired immigration of HSPC into the fetal liver resulting in anemia and embryonic lethality. These genetic experiments validated GATA4 as a molecular master regulator of hepatic angiodiversity, controlling LSEC specification and fetal liver development by establishing a hepatic niche required for proper HSPC [36]. Corresponding cellular experiments showed that GATA4 prevents, in cooperation with the transcriptional co-regulator $\mathrm{LMO} 3$, the autocrine induction of a pro-inflammatory phenotype while maintaining angiocrine signaling through the GATA4-downstream target BMP2 [59]. Interestingly, ectopic GATA4 overexpression in HUVEC resulted in the strong suppression of a continuous EC gene signature with a less stringent upregulation of LSEC-associated genes [36].

To bypass early embryonic lethality due to anemia when using Stab2-iCre to delete Gata4 in LSEC, recent experiments have employed $\mathrm{Clec} 4 \mathrm{~g}$-iCre for late embryonic deletion of Gata4 in LSEC (around E17.5) [60]. This experimental approach similarly led to induced LSEC-to-continuous EC differentiation including formation of a solid basement membrane resulting in liver fibrosis and hepatopathy in adult mice. Gata4-deficient LSEC started to express continuous EC genes as well as angiogenesis-related and profibrotic gene signatures including $M y c, P d g f b$, and Vegfa [61]. These experiments also showed that Gata4 deficiency in LSEC led to a de-repression of general (continuous) EC differentiation, which was mediated by increased chromatin accessibility when Gata4 was deleted. In turn, no changes on the chromatin level were seen in genes that were downregulated upon Gata4 deletion indicating that GATA4 has a strong repressive function on continuous EC differentiation on the chromatin level, whereas the activating functions are independent from alterations in chromatin accessibility [61]. Recent murine single-cell data from different vascular beds confirmed that Gata4 expression and the GATA4 transcriptional network are highly specific for hepatic EC [62].

As GATA4 is not sufficient to fully convert continuous EC into LSEC in vitro [36], other transcriptional regulators or angiocrine factors and microenvironmental regulators may be required to fully guide LSEC specification. Recent TF screenings for LSEC specification identified a combination of C-MAF, GATA4, and MEIS2 to induce LSEC signature genes in vitro such as CLEC4M, MRC1, LGMN, GPR182, PLXNC1, and SLCOA1 [63]. The study of human iPSC differentiating towards the LSEC lineage identified, based on motif analysis, additional potential TF candidates for LSEC differentiation including IRF2, ERG, MEIS2, SPI1, IRF7, WRNIP1, HIC2, NFIX_NFIB, BATF, and PATZ1, awaiting further in vitro and in vivo functional validation [64]. Similarly, functional LSEC-like cells could 
be generated from human pluripotent stem cells by a combination of hypoxia, cyclic AMP agonists, and TGF- $\beta$ inhibition. Venous pre-differentiation proved to be superior to support the expression of LSEC markers and functions than arterial pre-differentiation. Interestingly, venous angioblasts were able to engraft and differentiate in transplantation experiments into LSEC-like cells with expression of CD31, CD32b, and LYVE-1, formation of fenestrations and scavenging activity [54].

\section{Functional attributes of sinusoidal endothelial cells in health and disease}

\section{Blood flow and dynamics}

Within the hepatic sinusoids, LSEC are in direct contact to the circulating blood. They sense changes in blood pressure and shear stress in order to maintain low portal blood pressure to avoid microcirculatory dysfunction. LSEC cooperate with HSC to modulate vascular tone and contraction, producing and releasing vasoconstrictive cyclooxygenase 1 (COX1), thromboxane A2 (TXA2), and endothelin-1 (ET-1), as well as vasodilative nitric oxide (NO) and prostacyclin (see [65] for recent review). Interestingly, the transcription factor Kruppel-like factor (KLF)2 was shown to be induced in hepatic EC by increased shear stress controlling the upregulation of $\mathrm{NO}$, while downregulating vasoconstrictive ET-1 [66]. Thus, it is well established that LSEC respond to mechanical stretch; however, the mechanisms of mechanosensing and transduction of LSEC are not well studied. During development, the growth of the liver is highly dependent on blood perfusion, which activates $\beta 1$ integrins and VEGFR3 leading to hepatocyte growth factor (HGF) secretion. In the adult liver, mechano-transduction is sufficient to exert angiocrine HGF-signaling regulating proliferation and survival of hepatocytes. This indicates that balanced blood perfusion is critical for organ growth and also maintenance in the adult through angiocrine signaling mechanisms [67].

During aging, molecular changes in the cells of the liver sinusoids with diminished vasodilatory capacity resulting from reduced expression and phosphorylation of endothelial nitric oxide synthase (eNOS) or reduced NO bioavailability lead to elevated hepatic vascular resistance and increased portal blood pressure [68]. The aged hepatic vasculature strongly upregulates p16, a hallmark of cell senescence $[69,70]$. Senescent LSEC show transient upregulation of the scavenger receptors followed by a dramatic reduction of their clearance function during aging. Yet both, long-term and acute inactivation of LSEC p16 expression induces fibrosis [69]. Conversely, short-term ablation of p16 expressing LSEC reduced steatosis and inflammation in a murine NASH model [70].
Microcirculatory dysfunction is a hallmark of chronic liver disease and portal hypertension. Mechanosensitive angiocrine factors released by LSEC have been identified suggesting that portal hypertension may be promoted by neutrophil extracellular trap formation and development of microthrombi in the sinusoids. Mechanistically, stretching of LSEC resulted in the integrin-mediated activation of Piezo cation channels modulating Notch 1 activity. This led to the expression of neutrophil chemotactic chemokine CXCL1 via Hes/Hey nuclear translocation [71]. This newly identified mechanocrine pathway potentially offers novel therapeutic targets for treating portal hypertension, which is linked to liver failure and cirrhosis.

The transcription factor ERG contributes to maintaining an anti-thrombogenic environment in the microvasculature of the liver and the lungs. ERG acts in vascular beds with low shear stress as a chromatin opener for KLF2-dependent regulation of anticoagulant thrombomodulin expression [72]. But LSEC do not just modulate coagulation locally. They are also involved in systemic regulation of platelets and vascular thrombosis via Toll-like receptor (TLR)-2 expression. Recently, the microbiota-triggered expression of TLR2 by liver EC was identified as a novel innate immune signaling pathway regulating hepatic von Willebrand factor synthesis and thereby supporting arterial thrombus formation [73].

\section{Local and systemic clearance functions}

Next to passive transport mechanisms, enabled by open fenestrations and the absence of a basement membrane, such as the capacity to filter chylomicron remnants from the blood [74, 75] (Fig. 4a), LSEC are responsible for active clearance of soluble macromolecules, small particles, immune complexes, and lipopolysaccharides (Fig. 4b). In fact, LSEC are among the cells of the body with the highest endocytic capacity. They have numerous micropinocytotic and endocytotic vesicles which may contribute up to $45 \%$ of total pinocytic capacity [76]. As the liver serves as the primary detoxification organ of the body, it is essential that LSEC acquire strong lysosomal activity to eliminate waste molecules from the circulation. This clearance is mediated by endocytic and scavenger receptors on LSEC such as the mannose receptor (MRC1/CD206) [77], the Fc gamma-receptor IIb (FcgRII/ CD32b) [78], and hyaluronan receptors such as LYVE-1, STAB1, and STAB2 [79] (Fig. 4b). The mannose receptor, which is at much lower abundance also expressed by tissue resident macrophages, binds collagen peptides, tissue plasminogen activator, and lysosomal enzymes for catabolism of endocytosed material $[77,80]$. CD32b is responsible for the clearance of IgG-type immune complexes [81]. LSECexpressed STAB $1 / 2$ are involved in the clearance of noxious factors from the circulation, which has not only local, but 
(a)

Passive Clearance

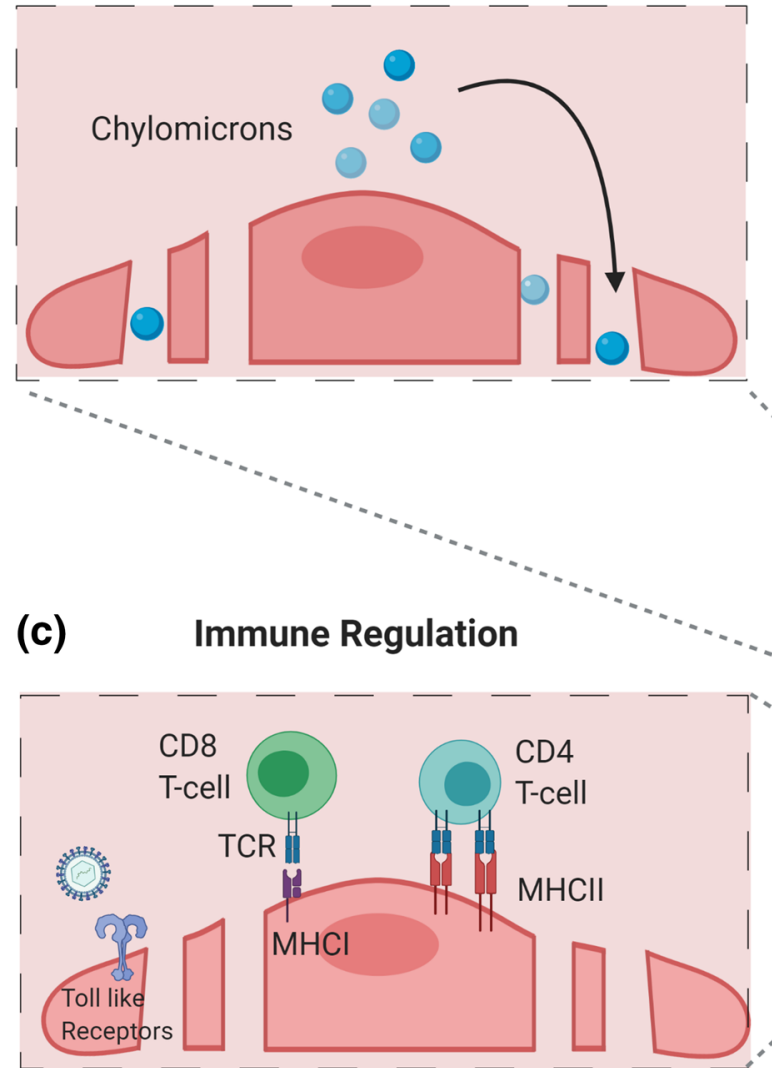

Fig. 4 Clearance and immunoregulatory functions of liver sinusoidal endothelial cell. LSEC have distinct organotypic functions capable of acting as professional scavengers and immunomodulators. a LSEClined sinusoids serve as conduits for the passive transfer of nutrients and soluble factors including circulating chylomicrons through open fenestrations. b LSEC execute active scavenger functions clearing pathogens, macromolecules, and waste products through expression of scavenger receptors such as mannose receptor, CD16, CD32b, Sta- (b)

Active Clearance

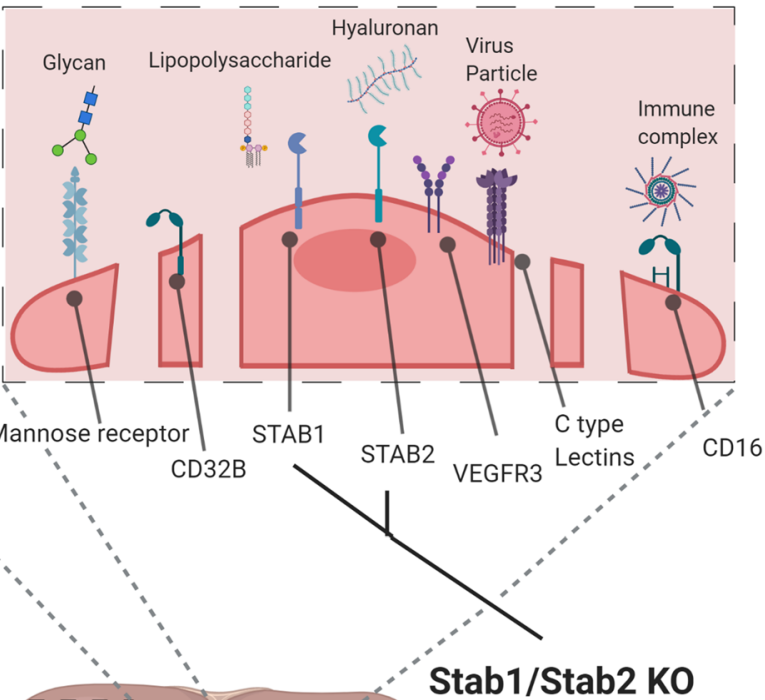

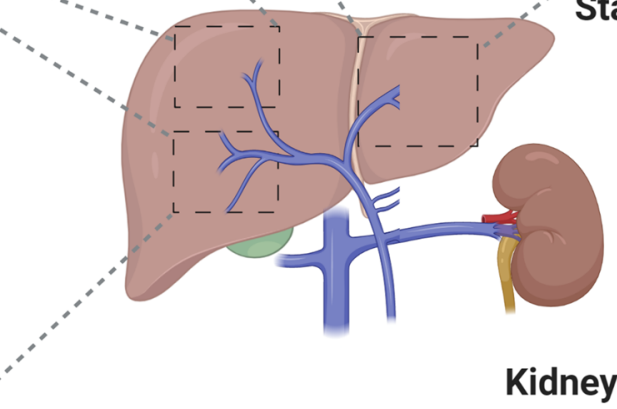

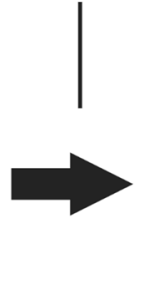

Kidney

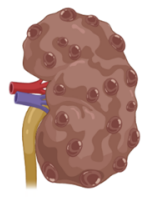

Kidney Fibrosis

bilin-1, Stabilin-2, VEGFR3, and C-type lectins. (C) LSEC play key roles in innate immunity by expressing Toll-like receptors (TLRs). They are also involved in regulating adaptive immunity. LSEC express major histocompatibility complex class I (MHC I) receptors to present antigens to $\mathrm{CD} 8+\mathrm{T}$ cells and major histocompatibility complex class II (MHC II) receptors to present antigens to CD4+ T cells

\section{Immunoregulatory functions}

neys [82] (Fig. 4). The stabilins act redundantly as revealed by the observation that mice deficient in either Stabl or Stab2 do no exhibit a major phenotype. In contrast, deletion of both, Stab1 and Stab2, resulted in premature mortality with severe glomerular kidney fibrosis and only mild liver fibrosis and dysfunction. Kidney transplantation from Stab1/2-double-deficient mice in wildtype mice prevented glomerular fibrosis, indicating the redundancy of STAB1 and STAB2 in the hepatic clearance of noxious factors from the blood.

Beyond scavenging of macromolecules, the repertoire of LSEC surface molecules enables regulatory functions in innate and adaptive immunity (see [83] for recent review) (Fig. 4c). Sinusoidal EC are exposed to a large number of gut-derived pathogens, which need to be removed from the circulation. Historically, KC, as liver-resident macrophage population, were considered to serve as the primary cell type responsible for blood clearance. More recently, LSEC gained increasing attention as primary gatekeeper of liver immune functions. Structurally, pathogens from the gut enter into the liver via portal vein forming portal ECs as the front line of host defense. LSEC have the ability to actively sense gut microbiota and control an immune zonation in the liver with 
periportal positioning of innate and adaptive immune cells to promote host defense, i.e., $\mathrm{KC}$-mediated protection from bacterial dissemination and sepsis in MYD88- and CXCL9dependent manner. LSEC-specific Myd88 and $\mathrm{Cxcl} 9$ null mice showed spatial disruption of $\mathrm{KC}$ indicating a pivotal role of portal ECs to establish the zone of hepatic immune defense [22]. Likewise, portal EC orchestrate monocyte recruitment and differentiation of KC through Notch-BMP pathway [21] (Fig. 5). Moreover, antigens are cleared by pattern recognition receptors expressed by LSEC. Among these, there are not only the aforementioned scavenger receptors STAB 1/2 and MRC1, but also TLR1-4, -6, -8, -9, and C-type lectin (CLEC) receptors (DC-SIGN/CLEC4L, L-SIGN/CLEC4M, LSECTIN/CLEC4G) [83].

LSEC are also highly efficient in clearing viral particles form the blood. DC-SIGN and L-SIGN are involved in the clearance of Ebola virus, Human Immunodeficiency Virus, and Corona viruses $[84,85]$. Moreover, Adenovirus 1 and BK/JC Polyoma-like particles have been shown to be rapidly

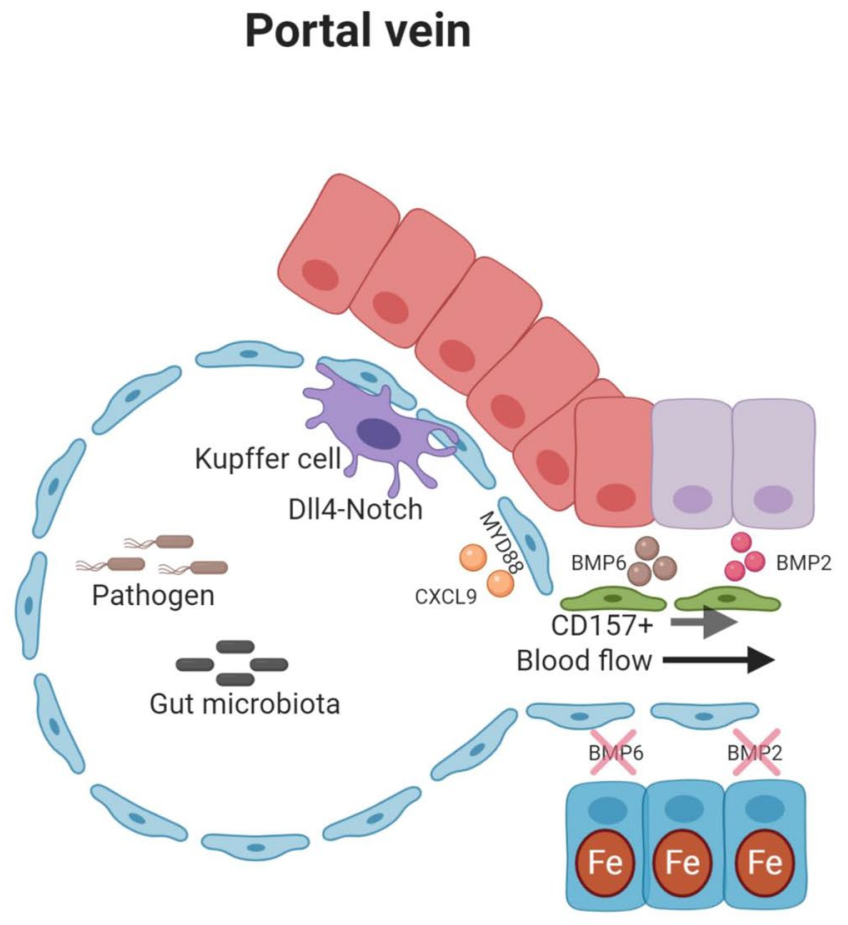

Fig. 5 Angiocrine factors control liver function. The hepatic endothelium is not just a passive conduit for blood. Instead, it acts as instructive gatekeeper regulating the hepatic microenvironment through EC-derived angiocrine factors. Pericentral LSEC are a prime example of angiocrine signaling. They modulate hepatocytic function, by secreting angiocrine Wnt2, Wnt9b, and Rspo3 to establish the spatial division of labor of hepatocytes ("metabolic liver zonation"). Concurrently, angiocrine Wnt-signaling fuels Axin $2^{+}, \mathrm{Lgr}^{+}$, and glutamine synthase $(\mathrm{GS})^{+}$pericentral hepatocytes to maintain the pericentral niche during tissue homeostasis. Moreover, angiocrine Wnt-signaling plays a pivotal role in regulating xenobiotic functions by modulat- and efficiently cleared by LSEC $[86,87]$. Beyond their function as a so-called "defendothelium" [88], immunotolerant properties of LSEC are imperative to limit hepatic inflammation and subsequent tissue damage, which may, for example, be lost during viral hepatitis by a shift from an anti-inflammatory towards a pro-inflammatory profile [89]. LSECdependent immunotolerance is induced by EC-mediated induction of IL10-producing Th1 cells [90] or Treg [91], or by suppression of Th1 and Th17 cells by IL10 secreted from LSEC which express MHC class II molecules. Vice versa, LSEC that also express MHC class I, are capable of cross-priming naïve CD8+ T cells [92] (Fig. 4c). Mediated by MRC1 receptor, LSEC can take up and process antigens to present them via MHC-I to CD8+ T cells, thereby promoting tolerance controlled by upregulated expression of co-inhibitory programmed cell death ligand 1 (PD-L1) [93, 94]. However, the promotion of tolerance is highly dependent on antigen concentration. While low antigen concentrations lead to tolerance, high amounts of harmful antigens

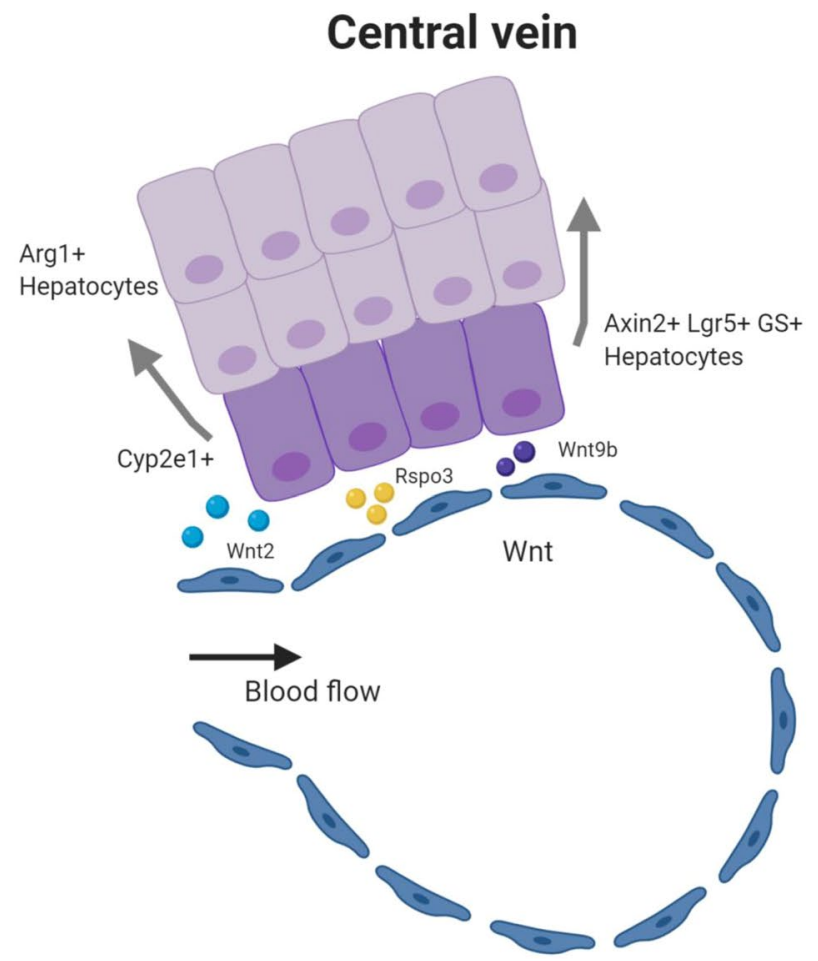

ing the hepatic cytochrome activity such as CYP2E1. In the portal zone, hepatocytes are actively involved in gluconeogenesis and urea cycle with increased expression of arginase (Arg1). Portal vein EC and periportal LSEC have high Notch activity with upregulated Dll4 expression. Angiocrine DLL4 may orchestrate monocyte recruitment to establish a niche for KC. Likewise, the hepatic immune zonation is further maintained by LSEC driven CXCL9 and through MYD88 pathway. Periportal LSEC also serve as a niche for resident LSEC progenitors expressing CD157. Midlobular LSEC control iron homeostasis by secretion of the angiocrine factors BMP2 and BMP6 
result in cross-priming of $\mathrm{CD} 8+\mathrm{T}$ cells enabling effector $\mathrm{T}$ cell responses [83, 95].

Recruitment of lymphocytes to LSEC is mediated by intercellular adhesion molecule-1, vascular adhesion protein-1 and STAB1 [96] and is further supported by low blood pressure and shear stress within the sinusoids. Beyond transcellular and paracellular migration, lymphocytes adhere to the hepatic endothelium to migrate across and along the LSEC layer, which is further enhanced by interferon- $y$ stimulation [97]. Independent of diapedesis, the uniquely fenestrated morphology of the sinusoids allows $\mathrm{T}$ cell foot processes to reach out into the space of Disse. They thereby get in physical contact with MHC-I expressing liver parenchymal cells to immunosurveillance hepatocytes, for example, to eliminate virus-infected cells. The initial arrest of T cells on LSEC may involve the docking to platelet aggregates adhering to sinusoidal hyaluronan bound via CD44. Interestingly, loss of LSEC fenestrae (capillarization) and fibrosis with increased deposition of ECM in the space of Disse impairs T cell immunosurveillance, which might limit viral host defense mechanisms and ultimately promote the development of hepatocellular carcinoma (HCC) [98].

\section{Vascular control of hepatocyte function}

Sieve plate fenestrations of LSEC separate the hepatic blood and the plasma in the space of Disse. These fenestrations enable the bi-directional transport of blood-borne molecules, metabolites, nutrients, and detoxification products to and from hepatocytes and HSC [99] (Fig. 1). The diverse metabolic functions of hepatocytes occur in different functional areas/zones within the liver lobule, whose positioning is controlled by distinct gene expression programs. This heterogeneity of hepatocytes is generally referred to as "metabolic liver zonation" (Fig. 1). Perturbation of metabolic liver zonation is regularly seen in non-alcoholic fatty liver disease (NAFLD), NASH, liver cirrhosis, and HCC [100]. While canonical Wnt- $\beta$-catenin signaling was identified as the decisive driver of metabolic zonation [101], the cellular origin of Wnt ligands remained unclear for many years. Recently, angiocrine Wnt ligands have received considerable attention. Both, inducible EC-specific deletion of the Wnt secretion mediator Evi/wntless $(E v i / W l s)$ as well as the inducible global deletion of the Wnt-signaling enhancer Rspo3 impair metabolic liver zonation and liver regeneration due to perturbed Wnt signaling in hepatocytes [12-14, 16, 102]. Detailed analysis of the angiocrine signaling mechanisms controlling metabolic zonation showed that Axin2positive pericentral hepatocyte progenitor cells expand over a period of one year from the pericentral area to the portal vein and replace preexisting trabecular hepatocytes. Inducible partial excision of endothelial $\mathrm{Evi} / \mathrm{Wl}$ caused angiocrine Wnt deficiency as well as loss of normal pericentral
Axin2-positive, glutamine synthetase (GS)-positive hepatocyte progenitor cells, i.e., loss of liver zonation, accompanied by reduced proliferation of pericentral hepatocytes and reduced liver regeneration. In fact, liver EC-derived angiocrine Wnt signaling controls not only metabolic liver zonation, but also total liver size. In turn, the corresponding intrahepatic EC zonation is not affected by deletion of EC-derived Wnt ligand secretion. Specifically, disruption of Evi/Wls from hepatic EC resulted in the loss of pericentral $\beta$-catenin target genes such as GS, RhBg, Axin2, and cytochrome $\mathrm{P} 450$ 2E1, and extended the expression of periportal genes such as arginase 1 (Fig. 5). Interestingly, ablation of angiocrine Wnt signaling also altered lipid metabolism by reducing plasma cholesterol levels and increasing total acylcarnitine blood levels which resembles mouse models of $\beta$-catenin signaling depletion in hepatocytes $[15$, 103-106].

Hepatocytes are well known for their ability to store iron. In this respect, another important gatekeeper function of sinusoidal EC was just recently identified with the demonstration that LSEC are a relevant source of BMP2 and BMP6 (Fig. 5). Secretion of LSEC-derived BMP2 and BMP6 controls iron metabolism in hepatocytes in a nonredundant angiocrine manner. Loss of endothelial BMP2 or BMP6 signaling caused severe iron overload in the liver and serum, similar to classic hereditary hemochromatosis, mediated by a reduced hepatocytic hepcidin expression, which is a key regulator of hepatocyte-controlled iron homeostasis $[17,18]$. The detailed mechanisms of iron sensing by LSEC, which lead to balanced BMP secretion and consecutive hepcidin expression, remain elusive.

The liver is a highly plastic organ with a remarkable capacity of scar-free tissue regeneration after acute injury, which is driven by guided proliferation of hepatocytes and non-parenchymal cells of the liver (Fig. 6). LSEC play an instructive role in regulating liver regeneration via angiocrine VEGFR2-DNA-binding protein inhibitor 1 (Id1)-Wnt2 and -HGF signaling to mediate hepatocyte proliferation [107] and susceptibility to necrosis after partial hepatectomy via HGF/c-Met involving Deptor to prevent excessive organ damage [108].

The Angiopoietin (Angpt)/Tie ligand/receptor system is another vascular signaling pathway that controls liver regeneration through intricate angiocrine signaling mechanisms. During the early inductive phase of liver regeneration (day $0-3$ ) following partial hepatectomy, LSEC expression of ANGPT2 is strongly downregulated resulting in downregulation of LSEC TGF- $\beta$ production and thereby the removal of an endogenous break of hepatocyte proliferation. The early phase of hepatocyte proliferation is followed by an angiogenic phase of tissue regeneration (4-8 day). During these later stages of liver regeneration, EC restore ANGPT2 expression which facilitates EC expression of VEGFR2 and 


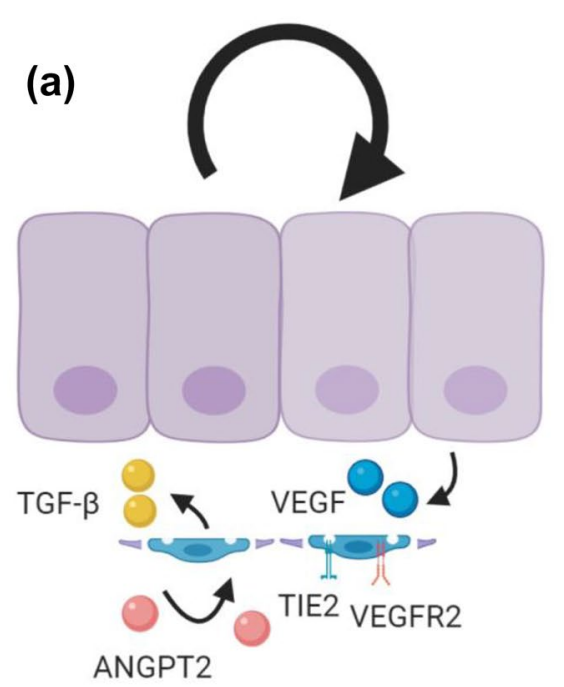

(c)
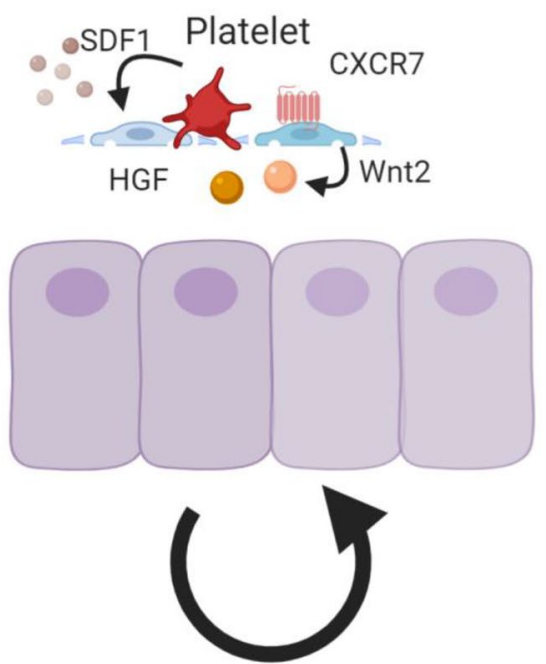

Fig. 6 Angiocrine control of liver regeneration. Angiocrine signaling is indispensable for liver regeneration. a During the early inductive phase of liver regeneration, downregulation of EC ANGPT2 leads to downregulation of TGF- $\beta$ production, thereby facilitating hepatocyte proliferation. During the later angiogenic phase, EC ANGPT2 production rebounds to control LSEC proliferation by regulating VEGFR2 in an autocrine Tie2-dependent manner in response to hepatocyte-derived VEGF. EC ANGPT2 thereby serves as a spatiotemporally regulated rheostat dynamically controlling regenerating hepatocytes and angiogenic EC. b The balance between pro-regenerative (CXCR7-Id1) and pro-fibrotic (CXCR4) pathways modulates

thereby leads to angiogenic EC proliferation in response to hepatocyte produced VEGF [109] (Fig. 6a). Additionally, stromal-derived factor-1 (SDF1)-receptors CXCR7 and CXCR4 balance regenerative (CXCR7-Id1) and profibrotic (CXCR4) programs. Following acute injury, CXCR7 is upregulated in LSEC to induce regenerative Wnt2, HGF, and angiogenic factors apelin and follistatin-like-1, whereas

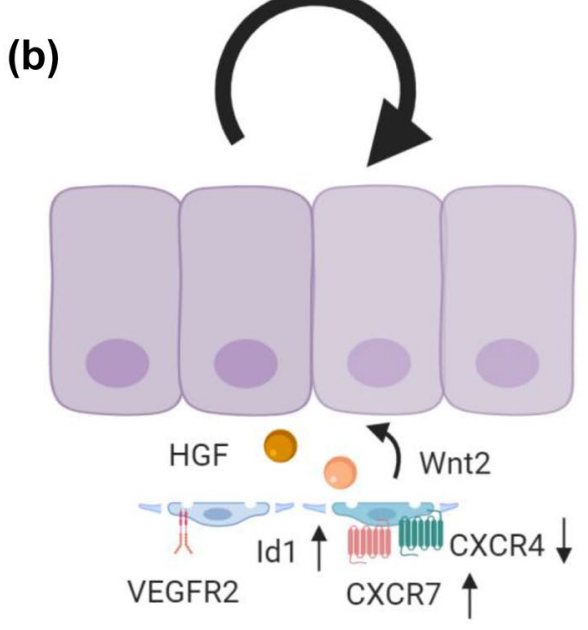

(d)

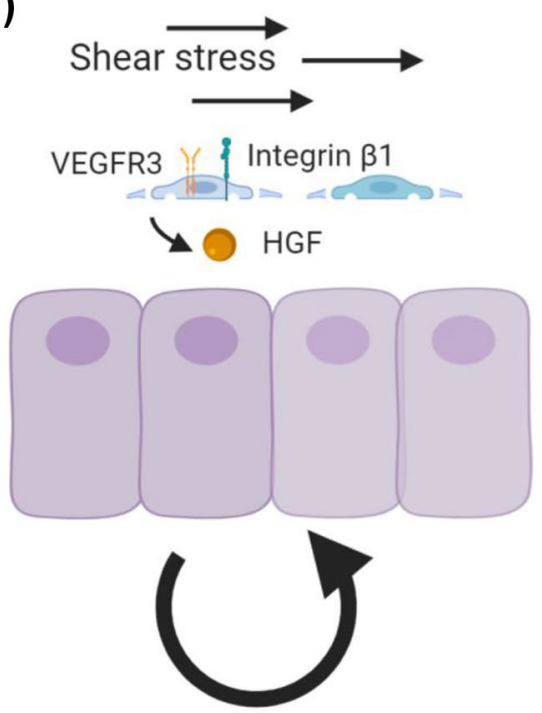

liver regeneration. The pro-regenerative CXCR7-Id1 pathway is upregulated during liver regeneration, to induce Wnt 2 and HGF. In addition to CXCR7, the VEGFR2-Id1-mediated pathway triggers the angiocrine factors Wnt2 and HGF to boost hepatocyte proliferation. c Activated platelets from the injured area release stromal-derived factor-1 (SDF1) to activate pro-regenerative CXCR7-mediated signaling. d Angiocrine HGF can be induced by blood perfusion-regulated mechano-sensing mechanisms. Increased blood flow resulting from hepatic injury upregulates VEGFR3 and $\beta 1$-integrins for HGF production

fibroblast growth factor receptor (FGFR)1-mitogen activated protein kinase-mediated CXCR4 upregulation and perturbation of CXCR7-Id1 signaling occurs after chronic injury [110] (Fig. 6b). Moreover, activated platelets may contribute to liver regeneration by secreting SDF1 to activate the LSEC-mediated regenerative CXCR7 pathway [111] (Fig. 6c). Correspondingly, transcriptional profiling of 
regenerating LSEC has uncovered regenerating angiocrine signatures such as $H G F, W n t 2$, Angpt2, BMP2, and MMP8 [4].

High-resolution mapping enabled to study dynamic transcriptional signatures and interactomes between hepatic cells during liver regeneration. The pseudotime analysis of regenerating LSEC has revealed dynamic states of LSEC activation confirming the imperative role of angiocrine $\mathrm{Wnt}$ and $\mathrm{HGF} / \mathrm{c}-\mathrm{Met}$ signaling during liver regeneration [112]. Furthermore, there is evidence that shear stress may induce LSEC-derived angiocrine signals during liver regeneration. As the perfusion pressure increases during the early phase of liver regeneration due to loss of liver mass, the dilation-induced mechano-transduction of LSEC is capable to upregulate integrin $\beta 1$ /VEGFR3 signaling, which further facilitates HGF production and c-Met signaling [67] (Fig. 6d). Vice versa, shear stress-induced TF expression modulates liver regeneration, as the shear-stress-instructed TF KLF2 in LSEC negatively regulates hepatocyte proliferation through induction of an antiproliferative secretome signature including activin A [113].

\section{Endothelial dysfunction and sinusoidal capillarization}

Endothelial dysfunction contributes to severe liver diseases ranging from alcoholic steatohepatitis and NASH to liver cirrhosis and from hepatocarcinogenesis to liver metastasis. During these disease processes, LSEC transdifferentiate towards a capillary phenotype in a process called "sinusoidal capillarization." This transdifferentiation process classically involves morphological changes including the loss of fenestrations and the formation of a continuous basement membrane [114]. These morphological changes are associated with a distinct molecular switch in EC marker expression from sinusoidal to continuous EC markers [36]. Sinusoidal capillarization of LSEC also occurs to some extent during aging with a reduction of fenestrations and increased thickening of LSEC resulting in hypoxia. This is referred to as "pseudocapillarization" and is mechanistically linked to age-related insulin resistance and hyperlipidemia $[68,115]$.

The loss of organ-specific endothelial differentiation impairs the capacity of LSEC to maintain HSC quiescence and thereby contributes to HSC activation and fibrotic liver disease (Fig. 7). Hence, restoration of LSEC differentiation results in HSC quiescence and resolution of liver fibrosis [26]. Secretion of VEGF from hepatocytes [37] and HSC is critical for maintaining the fenestrated LSEC phenotype via NO-dependent (VEGF-eNOS-soluble guanylyl cyclase (sGC)-cyclic guanosine monophosphate (cGMP)-protein kinase G) and NO-independent signaling mechanisms [26]. Thus, impairment of the eNOS-sGC-cGMP axis is a major cause of LSEC capillarization [116]. Notch signaling has emerged as another signaling pathway that controls the formation of fenestrae as Notch activation in LSEC results in the loss of fenestrae through altered eNOS-sGC signaling [117]. Moreover, fenestrations can be modulated in a paracrine manner by HSC-derived BMP9 leading to continuous EC differentiation with increased expression of the continuous EC marker CD34 and a reduced number of fenestrae [118].

Hedgehog (Hh) signaling is also involved in phenotypic changes during sinusoidal capillarization. In vitro capillarization of LSEC was associated with the repression of the Hh ligand inhibitor Hhip and induction of Hh downstream targets, evidenced by the finding that smoothened-deficient LSEC showed less capillarization as measured by a reduction of capillarization-associated genes and maintained fenestrations [119]. The liver X receptor (LXRa) transcription factor program was identified as a negative regulator of $\mathrm{Hh}$ signaling pathway thereby restoring LSEC differentiation. Capillarization of liver sinusoids was aggravated in a toxic liver fibrosis model in $L X R a$-deficient mice suggesting that LXR agonists are sufficient to maintain LSEC differentiated in vitro [120]. In turn, loss of platelet-derived growth factor (PDGF)B activity increases hepatic permeability, prevents sinusoidal capillarization, and improves insulin sensitivity [121].

\section{Vascular control of liver fibrosis and cirrhosis}

LSEC can integrate external stimuli to act as inductive regulators in fine-tuning physiological (regeneration) and pathological (fibrogenesis) responses to liver injury. Important signaling pathways and angiocrine factors in these processes include the VEGF-SDF1/CXCR4/CXCR7/FGFR1 system [110], the sphingosine1-phosphate receptor-1 (S1P1) [122], ERG via control of the TGF- $\beta$-SMAD signaling pathway [123], Notch as a regulator of eNOS-sGC [117], and the HGF/ NADPH oxidase (NOX) 4 axis [124]. The signaling pathways during liver fibrosis are complex and interdependent and vary substantially in different experimental models of fibrosis (Fig. 7). Induction of toxic liver injury by administration of carbon tetrachloride $\left(\mathrm{CCl}_{4}\right)$ results in a pericentral type of liver fibrosis with development of centroportal fibrotic septa, whereas bile duct ligation (BDL) as a surgery-based fibrosis model induces a portal pattern of fibrosis. Dietary mouse models recapitulating features of NASH such as the methionine- and choline-deficient diets (MCD) or the choline-deficient, L-amino acid-deficient diet (CDAA) present with steatohepatitis and a pericellular or perisinusoidal type of liver fibrosis [125].

In toxic liver fibrosis, pericentral hepatocyte damage is amplified by hepatocrine damage signals [126] that directly activate HSC [127] leading to bridging fibrosis between the central vein areas as a response to repair [128]. Capillarized 


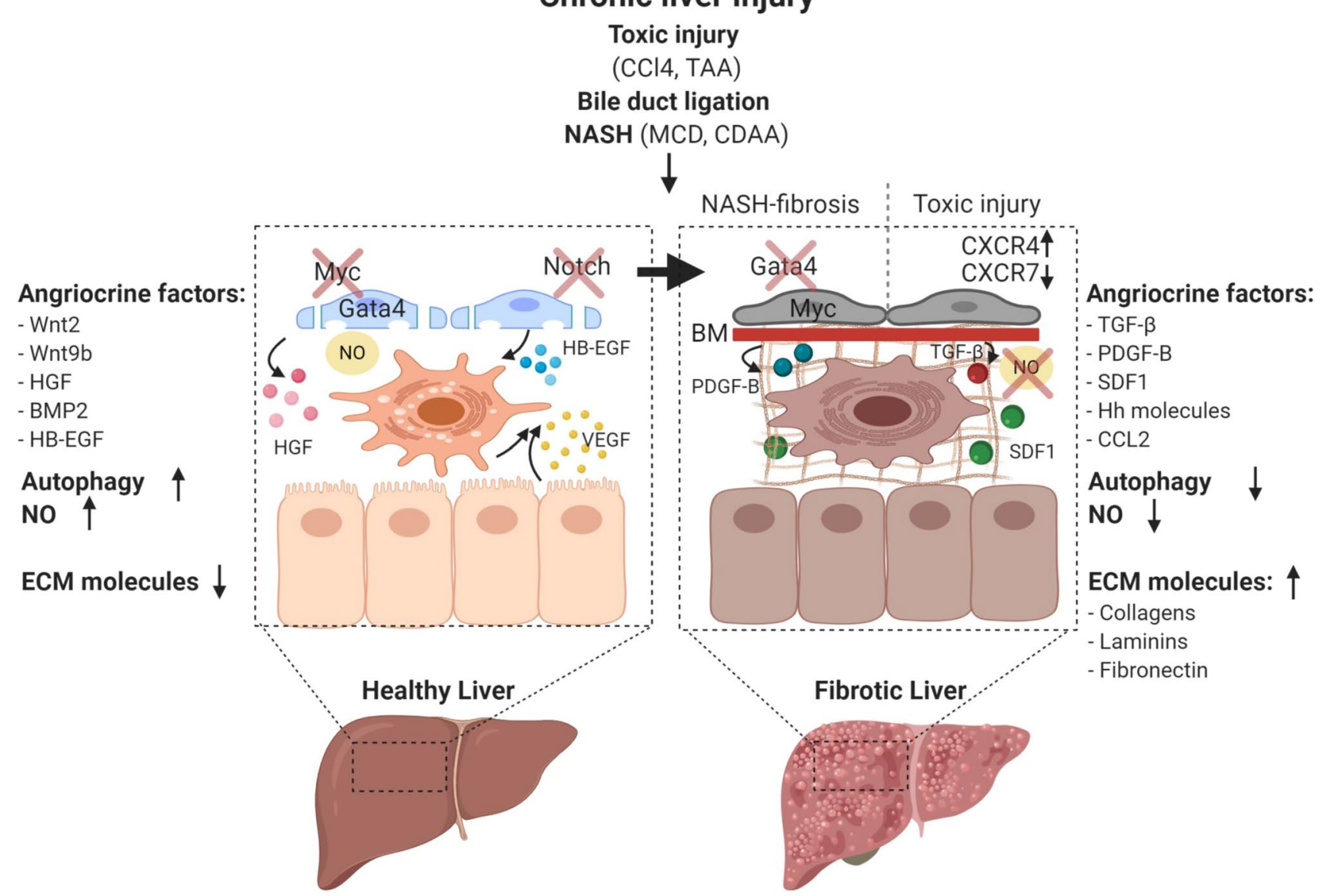

Fig. 7 Characteristics of liver sinusoidal endothelial cells during disease progression. Chronic liver damage can be experimentally induced by toxic substances such as carbon tetrachloride $\left(\mathrm{CCl}_{4}\right)$ and thioacetamide (TAA) administration, surgical interventions such as bile duct ligation, as well as dietary models of non-alcoholic steatohepatitis (NASH) including methionine- and choline-deficient diets (MCD) and the choline-deficient L-amino-defined diet (CDAA). LSEC maintain liver homeostasis through nitric oxide (NO) synthesis and secreting angiocrine factors such as Wnt2, Wnt9b, HGF, BMP2, p300 mediated CCL2, and heparin-binding EGF-like growth factor (HB-EGF). The transcription factor GATA4 controls the sinusoidal phenotype including the absence of a basement membrane.

LSEC in toxic liver fibrosis no longer prevent HSC activation [26], but exhibit a pro-fibrotic angiocrine program in LSEC with imbalance in activation from pro-regenerative CXCR7 to pro-fibrotic CXCR4 (FGFR $1^{+}, \mathrm{CXCR} 4^{+}$, TGF$\left.\beta^{+}, \mathrm{BMP}^{+}, \mathrm{PDGFC}^{+}, \mathrm{CXCR}^{-}, \mathrm{Id}^{-}\right)$that causes proliferation and expansion of Desmin-positive HSC [110]. In line with these findings, Notch activation in LSEC, resulting in sinusoidal capillarization by downregulated eNOS-sGC signaling, led to aggravated fibrogenesis in a $\mathrm{CCl}_{4}$-induced toxic liver fibrosis model, most likely due to increased TGF$\beta$-mediated HSC activation [117].

The transcription factor ERG controls TGF- $\beta /$ BMP-signaling in liver EC to maintain homeostasis and to protect
During liver homeostasis, autophagic activity of LSEC is increased to protect against liver injury, and there is only little deposition of ECM molecules in the space of Disse. GATA4 is downregulated and continuous EC genes including the transcription factor $M y c$ and the angiocrine factor $P d g f b$ are upregulated in NASH-induced perisinusoidal fibrosis. The balance between CXCR7 and CXCR4 shifts and further favors the pro-fibrotic pathways upon toxic liver injury. During fibrosis, angiocrine factors including TGF- $\beta$, PDGFB, SDF1, and $\mathrm{Hh}$ are dynamically upregulated. Activated LSEC may further trigger HSC to produce excessive ECM. NO bioavailability is lost and the autophagic activity is reduced

from liver fibrosis. $E R G$ deficiency in liver EC results in endothelial-to-mesenchymal transition (EndMT) and spontaneous liver fibrosis by a shift from SMAD1 signaling to profibrotic SMAD2/3 activity. Interestingly, ERG was found significantly downregulated in human fibrotic liver tissues from alcoholic liver disease and primary biliary cirrhosis patients [123]. Activation of endothelial S1P1 by its ligand HDL-bound S1P or S1P-agonist SEW2871 was identified as yet another anti-fibrotic and pro-regenerative pathway, attenuating toxic $\left(\mathrm{CCl}_{4}\right)$ and cholestatic (BDL) liver injury, while promoting functional recovery after partial hepatectomy [122]. 
Epigenetic mechanisms also impact liver fibrosis. The chromatin-remodeling protein BRG1 in liver EC controls liver fibrosis. EC-specific deletion of $\mathrm{Brg} \mathrm{l}$ decreased ROS production and EndMT leading to attenuation of liver fibrosis upon BDL-induced fibrosis. BRG1, by recruiting histone modifying enzymes, interacts with SMAD3 and AP-1 to induce NOX4 transcription and reactive oxygen species (ROS) production via TGF- $\beta$ [129]. Interestingly, NOX4 expression in perivascular cells correlated positively with the grade of fibrosis in human liver cirrhosis. As such, NOX4 was induced in perivascular cells of mice with EC-specific deletion of $\mathrm{HGF}$ upon partial hepatectomy or $\mathrm{CCl}_{4}$-induced fibrosis. A novel angiocrine pathway was thereby identified by which endothelial HGF suppresses perivascular NOX4 in order to stimulate fibrosis-free repair [124]. Furthermore, a pro-fibrotic effect of p300 signaling was demonstrated in LSEC by secretion of monocyte chemoattractant CCL2, which requires the formation of a $3300 / \mathrm{NFkB} / \mathrm{BRD} 4$ activator complex to promote acetylation at the CCL2 enhancer and promoter regions and, thus, may become an interesting target for treatment of portal hypertension and liver fibrosis [130].

Chronic liver injury in rats induced by thioacetamide (TAA) was shown to be associated with the recruitment of putative bone marrow-derived LSEC progenitors (so-called "sproc" cells), which engraft into the liver and contribute to fibrosis but fail to fully differentiate into LSEC due to downregulated VEGF-eNOS-NO-sGC-cGMP pathway signaling under the control of TGF- $\beta$, thrombospondin 1 (TSP-1), and a disintegrin and metalloproteinase (ADAM) TS13 [131]. Heparin-binding epidermal growth factor-like growth factor (HB-EGF) was identified in this setting as a relevant angiocrine factor which is shed from the cytosolic membrane of LSEC by ADAMs/MMPs in the normal liver to maintain HSC quiescence [131]. This is further supported by the fact that liver fibrosis is exacerbated in $H B-E G F \mathrm{KO}$ mice [132, 133].

There is also experimental evidence to suggest that the autophagic activity of LSEC modulates sinusoidal capillarization and LSEC dysfunction by decreasing NO bioavailability and ROS activation. Deletion of the essential autophagy gene Atg7 in LSEC aggravates liver fibrosis following $\mathrm{CCl}_{4}$ challenge by activating $\mathrm{HSC}$ potentially via increased oxidative stress while inflammation and liver damage are not remarkably altered [134]. Autophagy has previously been shown to protect LSEC during the early phase of toxic liver injury. Yet, autophagy is also relevant in LSEC during NASH. Notably, a defect in autophagy could be detected in LSEC from NASH patients. Moreover, deficiency of autophagy induced in mice by deleting Atg 5 in EC promoted NASH and liver fibrosis. In contrast to the acute $\mathrm{CCl}_{4}$ exposure, high-fat diet as a model of fatty liver disease as well as of administration of $\mathrm{CCl}_{4}$ for 6 weeks led to inflammation and liver injury, thereby resulting in increased perisinusoidal liver fibrosis [135].

Fibrosis during NASH starts with perisinusoidal fibrosis and is caused by a cascade of multiple sequential pathogenic hits leading to damage of hepatocytes, but also non-parenchymal liver cells [136]. Among the non-parenchymal cells of the hepatic vascular niche, LSEC play a pivotal role in NASH development $[137,138]$. Notably, mice fed a CDAA diet exhibited a reduction in fenestrations within one week of diet prior to the onset of steatosis. These findings are in line with genetic inactivation experiments of the plasmalemma vesicle-associated protein (PLVAP) in mice. Knockout of $P L V A P$ led to a reduction of fenestrations resulting in elevated serum levels of triglycerides, LDL, and cholesterol. As a consequence, $P V L A P$-deficient mice spontaneously developed a perisinusoidal type of liver fibrosis as seen in NASH [75].

A recently established single-cell crosstalk map of nonparenchymal cells of Amylin diet-induced NASH revealed a remarkably maintained heterogeneity of LSEC, which could be categorized as periportal, pericentral, and two midzonal LSEC populations. However, LSEC underwent a significant molecular transdifferentiation with increased gene signatures for lipid metabolism, antigen presentation, and chemokine release, whereas genes related to vascular development and homeostasis were downregulated. Moreover, well-known angiocrine factors and receptors such as $B M P 2, W n t 2$, and Gpr182 were significantly downregulated in NASH livers [139]. These findings are in line with recent findings showing that LSEC gene signatures including transcription factor Gata4 are significantly downregulated in a CDAAdiet-induced NASH model with perisinusoidal liver fibrosis, whereas continuous EC genes are induced including MYC target genes and the HSC-activating cytokine $P d g f b$, which is not expressed by healthy, resting LSEC [61]. Notably, these transcriptomic changes are compatible with alterations in the liver following LSEC-restricted Gata4 deletion, which results in sinusoidal capillarization, hepatopathy, and perisinusoidal liver fibrosis without changes in hepatic triglyceride levels. Gata4 deletion in LSEC similarly induced $M y c, P d g f b$, and other pro-fibrotic angiocrine factors such as Esm1, Igfbp5, and Sparcl1, whereas BMP2 and Wnt2 were downregulated. Mechanistically, Gata4 deficiency in LSEC leads to de-repression of continuous EC differentiation by increasing chromatin accessibility allowing MYC-dependent activation of PDGFB. This suggests that downregulation of Gata4 and its downstream targets is an important pathogenetic factor in CDAA-induced perisinusoidal fibrosis leading to a pro-fibrotic switch in angiocrine signaling [61].

The findings in Gata4-deficient mice have been fully confirmed by LSEC single-cell RNAseq data from human cirrhotic livers, which similarly suggest antagonistic functions of GATA4 and MYC with downstream disturbance of 
the PDGFB/PDGF receptor (R) $\beta$ signaling axis [140]. This extensive RNAseq analysis identified two disease-specific LSEC clusters in cirrhotic livers, which were defined as $C D 3$ $4^{+} P L V A P^{+} V W A I^{+}$and $C D 34^{+} P L V A P^{+} A C K R 1^{+}$. These two clusters co-express pro-fibrogenic genes such as $P D G F D$, $P D G F B, L O X, L O X L 2$ and display an immunomodulatory phenotype, enhancing leukocyte transmigration potentially via ACKR1. LSEC from the fibrotic niche actively interact with HSC to promote ECM protein deposition via PDGFR, TNFRSF12A, and Notch signaling pathways. In contrast, "healthy" $C D 34 C L E C 4 M^{+} \mathrm{EC}$, which were annotated as LSEC, were reduced in cirrhotic livers [140]. Concurrently, additional EC markers related to EC dysfunction and capitalization were observed during liver fibrosis, such as Fabp4, Pcdh17, CD34, and Esml [141]. While transdifferentiation of LSEC during disease progression is well established, EC heterogeneity is to some extent conserved even during advanced stages of cirrhosis. Notably, pericentral LSEC were shown to be more susceptible to damage with increased signature changes of capillarization compared to EC subpopulations from other regions [142].

Advanced liver fibrosis and cirrhosis are major risk factors for the development of HCC. The angiogenic activity of $\mathrm{HCC}$ has been correlated with high risk of microvascular invasion, metastasis, and poor prognosis. Similar to sinusoidal capillarization in liver fibrosis and cirrhosis, transdifferentiation of the sinusoidal vasculature is observed in human and murine HCC with loss of LSEC markers STAB1, STAB2, LYVE-1, CD32b, and GPR182 and induction of the continuous EC marker CD31 [143, 144]. The loss of STAB2 expression in peri-tumorous liver tissue from HCC patients is associated with extended overall survival [143]. These findings correspond well with recent single-cell RNAseq data analyzing EC heterogeneity in livers from HDD-induced and HT-29 tumors. Liver tumor-associated EC did not express LSEC, portal vein EC or central vein EC markers, but a signature related to portal vein EC (CD63, Ehd4, CD200) as well as Aplnr and Coll8al. Interestingly, $\mathrm{EC}$ adjacent to the tumor showed molecular characteristics with an intermediate state between normal LSEC and tumor endothelium [145]. The detailed comparative mouse/ human single-cell RNAseq analysis of EC in HCC identified increased NRP1,VEGFR2, and PLVAP expression [146]. Correspondingly, EC from the fetal liver were found to express PLVAP and VEGFR2, reflecting the oncofetal nature of HCC angiogenesis. Concurrently, FOLR2 expressing tumor-associated macrophages, a gatekeeper of the immunosuppressive milieu, have been detected in both HCC and fetal liver reflecting the tight interplay between EC and macrophages. Indeed, the oncofetal reprogramming is maintained by hepatocyte-derived VEGF and direct cell-tocell interactions of EC and macrophages via Notch signaling [146].

\section{Perspectives}

The recent advances in cell separation and bulk transcriptomics as well as single-cell RNA sequencing techniques have enabled the identification of distinct LSEC molecular programs and led to the identification of LSEC subpopulations in a hitherto unparalleled level of resolution. As discussed in detail in this review, Id1 [107], LXR- $\alpha$ [120], endothelial Notch signaling [60, 117, 147, 148], KLF2 [113], and ERG [123] act as regulators of differentiated LSEC programs. However, only GATA4 can so far be considered as master regulator of sinusoidal EC specification. GATA4 is non-redundantly required for liver development [36] and to maintain LSEC homeostasis in the adult [61]. The recent identification of the GATA4/MYC/PDGFB/ PDGFR $\beta$ axis in LSEC as critical regulator of liver fibrogenesis offers a novel targetable pathway for angiotargeted therapies [149, 150]. Unfortunately, upstream mechanisms regulating GATA4 expression in LSEC still remain elusive. Moreover, the molecular programs of LSEC zonation into pericentral, midlobular, and periportal subtypes with a distinct EC marker and angiocrine profile, but also structural and functional differences are still largely unexplored. Future work will have to address which transcription factors are responsible for LSEC zonation. It may well be that different combinations of transcriptional regulators, epigenetic mechanisms, or microenvironmental factors (oxygen and nutrient levels, niche cell heterogeneity) serve in a concerted manner as drivers of intra-organ EC specification and zonation.

While sinusoidal EC in the liver have been extensively studied for their organotypic functions, much less is known about angiodiversity and organotypic functions of sinusoidal EC in other organs. Sinusoidal EC are also found in the spleen, bone marrow, lymphoid tissues, and endocrine organs [6], and transcriptomic analyses revealed molecular similarities, especially for liver, spleen, and bone marrow EC $[4,62]$. Similar to the intra-organ angiodiversity in the liver, the BM microvasculature comprises a highly complex system composed of distinct vessel types that were shown to contribute to bone formation and HSPC maintenance and differentiation [151-155]. Not only differences in permeability, but also oxygen levels and flow, between less permeable $\mathrm{BM}$ arterial EC, H-type capillary vessels and highly permeable and fenestrated BM sinusoidal EC (SEC) have been proposed to regulate HSPC proliferation and homing [151]. However, the exact role of BM SEC, the most abundant cell type in the BM microenvironment, in HSC maintenance and differentiation remains less well defined as is the influence of distinct vascular niche cells during development and progression of hematological disorders. Of note, exploring the in vivo functions of distinct cell types and cellular subpopulations within the BM microenvironment such as BM SEC 
remains challenging, especially due to the lack of suitable highly specific Cre-driver mice.

Notch activation in hepatic EC results in sinusoidal capillarization, impaired metabolic liver zonation and aggravation of $\mathrm{CCl}_{4}$-induced liver fibrosis, suggesting that Notch inhibition may protect from sinusoidal capillarization [117]. While this may provide opportunities for Notch-targeted therapies, contextual organ- and disease-specific functions of Notch signaling must be taken into consideration. In the liver, Notch inhibition promotes hepatic metastases [156] and vice versa, Notch activation protects against liver metastasis of melanoma and colorectal cancer [60]. In contrast, Notch activation in the lung promotes lung metastasis [157].

The better understanding of LSEC angiodiversity may also pave the way towards novel immune-targeted therapies. For example, melittin nanoparticles could recently be shown to modulate LSEC immune functions and thereby suppress liver metastasis [158]. Likewise, the recent breakthrough developments in HCC therapy with the combination of immune checkpoint inhibition (PD-L1) and antiangiogenesis (VEGF), essentially doubling the therapeutic efficacy of the established standard of care (Sorafenib), ask for a concerted effort aimed at dissecting the mechanism of action of the observed therapeutic synergy, and particularly how and to what extent LSEC angiodiversity contributes to facilitating immune checkpoint-targeted therapy [159]. And beyond cancer, the ability of LSEC to balance defense mechanisms and immunosuppression may lead to novel therapeutic strategies to combat chronic inflammatory and autoimmune-related liver diseases.

Acknowledgements The authors regret that, owing to space limitations, they could not cite all original research articles and related references on this topic. Work in the authors' lab on the structural and functional analysis of the liver vasculature is supported by grants from the Deutsche Forschungsgemeinschaft (CRC1366 'Vascular Control of Organ Function' [Project Number 39404578 to P.-S.K, S.G. and H.G.A.], CRC-TR209 'Liver Cancer' [project number 314905040 to S.G. and H.G.A.], CRC1324 'Wnt signaling' [Project Number 331351713] to HGA], RTG2099 "Hallmarks of Skin Cancer" [Project Number 259332240 to P.-S.K, S.G. and H.G.A.] as well as the European Research Council Advanced Grant 'AngioMature' [Project 787181 to H.G.A.]. Figures were generated with biorender.com.

Funding Open Access funding enabled and organized by Projekt DEAL.

Open Access This article is licensed under a Creative Commons Attribution 4.0 International License, which permits use, sharing, adaptation, distribution and reproduction in any medium or format, as long as you give appropriate credit to the original author(s) and the source, provide a link to the Creative Commons licence, and indicate if changes were made. The images or other third party material in this article are included in the article's Creative Commons licence, unless indicated otherwise in a credit line to the material. If material is not included in the article's Creative Commons licence and your intended use is not permitted by statutory regulation or exceeds the permitted use, you will need to obtain permission directly from the copyright holder. To view a copy of this licence, visit http://creativecommons.org/licenses/by/4.0/.

\section{References}

1. Aird WC (2007) Phenotypic heterogeneity of the endothelium: II. Representative vascular beds. Circ Res 100(2):174-190. https:// doi.org/10.1161/01.RES.0000255690.03436.ae

2. Auerbach R, Alby L, Morrissey LW, Tu M, Joseph J (1985) Expression of organ-specific antigens on capillary endothelial cells. Microvasc Res 29(3):401-411. https://doi.org/10.1016/ 0026-2862(85)90028-7

3. Kumar S, West DC, Ager A (1987) Heterogeneity in endothelial cells from large vessels and microvessels. Differentiation 36(1):57-70. https://doi.org/10.1111/j.1432-0436.1987.tb001 81. $\mathrm{x}$

4. Nolan DJ, Ginsberg M, Israely E, Palikuqi B, Poulos MG, James D, Ding BS, Schachterle W, Liu Y, Rosenwaks Z, Butler JM, Xiang J, Rafii A, Shido K, Rabbany SY, Elemento O, Rafii S (2013) Molecular signatures of tissue-specific microvascular endothelial cell heterogeneity in organ maintenance and regeneration. Dev Cell 26(2):204-219. https://doi.org/10.1016/j.devcel.2013.06.017

5. Jakab M, Augustin HG (2020) Understanding angiodiversity: insights from single cell biology. Development 147(15):dev146621. https://doi.org/10.1242/dev.146621

6. Augustin HG, Koh GY (2017) Organotypic vasculature: from descriptive heterogeneity to functional pathophysiology. Science 357(6353):2379. https://doi.org/10.1126/science.aal2379

7. Xie G, Wang L, Wang X, Wang L, DeLeve LD (2010) Isolation of periportal, midlobular, and centrilobular rat liver sinusoidal endothelial cells enables study of zonated drug toxicity. Am J Physiol Gastrointest Liver Physiol 299(5):G1204-1210. https:// doi.org/10.1152/ajpgi.00302.2010

8. Aizarani N, Saviano A, Sagar, Mailly L, Durand S, Herman JS, Pessaux P, Baumert TF, Grun D (2019) A human liver cell atlas reveals heterogeneity and epithelial progenitors. Nature 572(7768):199-204. https://doi.org/10.1038/s41586-019-1373-2

9. Halpern KB, Shenhav R, Massalha H, Toth B, Egozi A, Massasa EE, Medgalia C, David E, Giladi A, Moor AE, Porat Z, Amit I, Itzkovitz S (2018) Paired-cell sequencing enables spatial gene expression mapping of liver endothelial cells. Nat Biotechnol 36(10):962-970. https://doi.org/10.1038/nbt.4231

10. Halpern KB, Shenhav R, Matcovitch-Natan O, Toth B, Lemze D, Golan M, Massasa EE, Baydatch S, Landen S, Moor AE, Brandis A, Giladi A, Avihail AS, David E, Amit I, Itzkovitz S (2017) Single-cell spatial reconstruction reveals global division of labour in the mammalian liver. Nature 542(7641):352-356. https://doi.org/10.1038/nature21065

11. Ma R, Martinez-Ramirez AS, Borders TL, Gao F, Sosa-Pineda B (2020) Metabolic and non-metabolic liver zonation is established non-synchronously and requires sinusoidal Wnts. Elife 9:e36206. https://doi.org/10.7554/eLife.46206

12. Planas-Paz L, Orsini V, Boulter L, Calabrese D, Pikiolek M, Nigsch F, Xie Y, Roma G, Donovan A, Marti P, Beckmann N, Dill MT, Carbone W, Bergling S, Isken A, Mueller M, Kinzel B, Yang Y, Mao X, Nicholson TB, Zamponi R, Capodieci P, Valdez R, Rivera D, Loew A, Ukomadu C, Terracciano LM, Bouwmeester T, Cong F, Heim MH, Forbes SJ, Ruffner H, Tchorz JS (2016) The RSPO-LGR4/5-ZNRF3/RNF43 module controls liver zonation and size. Nat Cell Biol 18(5):467-479. https://doi.org/ $10.1038 /$ ncb3337 
13. Rocha AS, Vidal V, Mertz M, Kendall TJ, Charlet A, Okamoto $\mathrm{H}$, Schedl A (2015) The angiocrine factor Rspondin3 is a key determinant of liver zonation. Cell Rep 13(9):1757-1764. https:// doi.org/10.1016/j.celrep.2015.10.049

14. Wang B, Zhao L, Fish M, Logan CY, Nusse R (2015) Self-renewing diploid Axin2(+) cells fuel homeostatic renewal of the liver. Nature 524(7564):180-185. https://doi.org/10.1038/nature14863

15. Leibing T, Geraud C, Augustin I, Boutros M, Augustin HG, Okun JG, Langhans CD, Zierow J, Wohlfeil SA, Olsavszky V, Schledzewski K, Goerdt S, Koch PS (2018) Angiocrine Wnt signaling controls liver growth and metabolic maturation in mice. Hepatology 68(2):707-722. https://doi.org/10.1002/hep.29613

16. Preziosi M, Okabe H, Poddar M, Singh S, Monga SP (2018) Endothelial Wnts regulate beta-catenin signaling in murine liver zonation and regeneration: A sequel to the Wnt-Wnt situation. Hepatol Commun 2(7):845-860. https://doi.org/10.1002/hep4. 1196

17. Canali S, Zumbrennen-Bullough KB, Core AB, Wang CY, Nairz M, Bouley R, Swirski FK, Babitt JL (2017) Endothelial cells produce bone morphogenetic protein 6 required for iron homeostasis in mice. Blood 129(4):405-414. https://doi.org/10.1182/ blood-2016-06-721571

18. Koch PS, Olsavszky V, Ulbrich F, Sticht C, Demory A, Leibing T, Henzler T, Meyer M, Zierow J, Schneider S, Breitkopf-Heinlein K, Gaitantzi H, Spencer-Dene B, Arnold B, Klapproth K, Schledzewski K, Goerdt S, Geraud C (2017) Angiocrine $\mathrm{Bmp} 2$ signaling in murine liver controls normal iron homeostasis. Blood 129(4):415-419. https://doi.org/10. 1182/blood-2016-07-729822

19. Wakabayashi T, Naito H, Suehiro JI, Lin Y, Kawaji H, Iba T, Kouno T, Ishikawa-Kato S, Furuno M, Takara K, Muramatsu F, Weizhen J, Kidoya H, Ishihara K, Hayashizaki Y, Nishida K, Yoder MC, Takakura N (2018) CD157 marks tissue-resident endothelial stem cells with homeostatic and regenerative properties. Cell Stem Cell 22(3):384-397. https://doi.org/10.1016/j. stem.2018.01.010

20. Khan JA, Mendelson A, Kunisaki Y, Birbrair A, Kou Y, ArnalEstape A, Pinho S, Ciero P, Nakahara F, Ma'ayan A, Bergman A, Merad M, Frenette PS (2016) Fetal liver hematopoietic stem cell niches associate with portal vessels. Science 351(6269):176-180. https://doi.org/10.1126/science.aad0084

21. Bonnardel J, T'Jonck W, Gaublomme D, Browaeys R, Scott CL, Martens L, Vanneste B, De Prijck S, Nedospasov SA, Kremer A, Van Hamme E, Borghgraef P, Toussaint W, De Bleser P, Mannaerts I, Beschin A, van Grunsven LA, Lambrecht BN, Taghon T, Lippens S, Elewaut D, Saeys Y, Guilliams M (2019) Stellate cells, hepatocytes, and endothelial cells imprint the kupffer cell identity on monocytes colonizing the liver macrophage niche. Immunity 51(4):638-654. https://doi.org/10.1016/j.immuni. 2019.08.017

22. Gola A, Dorrington MG, Speranza E, Sala C, Shih RM, Radtke AJ, Wong HS, Baptista AP, Hernandez JM, Castellani G, Fraser IDC, Germain RN (2021) Commensal-driven immune zonation of the liver promotes host defence. Nature 589(7840):131-136. https://doi.org/10.1038/s41586-020-2977-2

23. Neubauer K, Kruger M, Quondamatteo F, Knittel T, Saile B, Ramadori G (1999) Transforming growth factor-betal stimulates the synthesis of basement membrane proteins laminin, collagen type IV and entactin in rat liver sinusoidal endothelial cells. J Hepatol 31(4):692-702. https://doi.org/10.1016/s0168-8278(99) 80350-x

24. Tsuchida T, Friedman SL (2017) Mechanisms of hepatic stellate cell activation. Nat Rev Gastroenterol Hepatol 14(7):397-411. https://doi.org/10.1038/nrgastro.2017.38

25. Pasarin M, La Mura V, Gracia-Sancho J, Garcia-Caldero H, Rodriguez-Vilarrupla A, Garcia-Pagan JC, Bosch J, Abraldes JG
(2012) Sinusoidal endothelial dysfunction precedes inflammation and fibrosis in a model of NAFLD. PLoS One 7(4):e32785. https://doi.org/10.1371/journal.pone.0032785

26. Deleve LD, Wang X, Guo Y (2008) Sinusoidal endothelial cells prevent rat stellate cell activation and promote reversion to quiescence. Hepatology 48(3):920-930. https://doi.org/10.1002/hep. 22351

27. Poisson J, Lemoinne S, Boulanger C, Durand F, Moreau R, Valla D, Rautou PE (2017) Liver sinusoidal endothelial cells: physiology and role in liver diseases. J Hepatol 66(1):212-227. https:// doi.org/10.1016/j.jhep.2016.07.009

28. Wisse E (1970) An electron microscopic study of the fenestrated endothelial lining of rat liver sinusoids. J Ultrastruct Res 31(1):125-150. https://doi.org/10.1016/s0022-5320(70)90150-4

29. Braet F, De Zanger R, Baekeland M, Crabbe E, Van Der Smissen P, Wisse E (1995) Structure and dynamics of the fenestraeassociated cytoskeleton of rat liver sinusoidal endothelial cells. Hepatology 21(1):180-189

30. Wisse E, De Zanger RB, Charels K, Van Der Smissen P, McCuskey RS (1985) The liver sieve: considerations concerning the structure and function of endothelial fenestrae, the sinusoidal wall and the space of Disse. Hepatology 5(4):683-692. https:// doi.org/10.1002/hep.1840050427

31. Zapotoczny B, Szafranska K, Kus E, Braet F, Wisse E, Chlopicki S, Szymonski M (2019) Tracking fenestrae dynamics in live murine liver sinusoidal endothelial cells. Hepatology 69(2):876888. https://doi.org/10.1002/hep.30232

32. Couvelard A, Scoazec JY, Dauge MC, Bringuier AF, Potet F, Feldmann G (1996) Structural and functional differentiation of sinusoidal endothelial cells during liver organogenesis in humans. Blood 87(11):4568-4580

33. Matsumoto K, Yoshitomi H, Rossant J, Zaret KS (2001) Liver organogenesis promoted by endothelial cells prior to vascular function. Science 294(5542):559-563. https://doi.org/10.1126/ science. 1063889

34. Lotto J, Drissler S, Cullum R, Wei W, Setty M, Bell EM, Boutet SC, Nowotschin S, Kuo YY, Garg V, Pe'er D, Church DM, Hadjantonakis AK, Hoodless PA (2020) Single-cell transcriptomics reveals early emergence of liver parenchymal and non-parenchymal cell lineages. Cell 183(3):702-716. https://doi.org/10.1016/j. cell.2020.09.012

35. Gomez Perdiguero E, Klapproth K, Schulz C, Busch K, Azzoni E, Crozet L, Garner H, Trouillet C, de Bruijn MF, Geissmann F, Rodewald HR (2015) Tissue-resident macrophages originate from yolk-sac-derived erythro-myeloid progenitors. Nature 518(7540):547-551. https://doi.org/10.1038/nature13989

36. Geraud C, Koch PS, Zierow J, Klapproth K, Busch K, Olsavszky V, Leibing T, Demory A, Ulbrich F, Diett M, Singh S, Sticht C, Breitkopf-Heinlein K, Richter K, Karppinen SM, Pihlajaniemi T, Arnold B, Rodewald HR, Augustin HG, Schledzewski K, Goerdt S (2017) GATA4-dependent organ-specific endothelial differentiation controls liver development and embryonic hematopoiesis. J Clin Invest 127(3):1099-1114. https://doi.org/10.1172/JCI90 086

37. Walter TJ, Cast AE, Huppert KA, Huppert SS (2014) Epithelial VEGF signaling is required in the mouse liver for proper sinusoid endothelial cell identity and hepatocyte zonation in vivo. Am J Physiol Gastrointest Liver Physiol 306(10):G849-862. https:// doi.org/10.1152/ajpgi.00426.2013

38. Zhang H, Pu W, Tian X, Huang X, He L, Liu Q, Li Y, Zhang L, He L, Liu K, Gillich A, Zhou B (2016) Genetic lineage tracing identifies endocardial origin of liver vasculature. Nat Genet 48(5):537-543. https://doi.org/10.1038/ng.3536

39. Goldman O, Han S, Hamou W, Jodon de Villeroche V, Uzan G, Lickert H, Gouon-Evans V (2014) Endoderm generates 
endothelial cells during liver development. Stem Cell Rep 3(4):556-565. https://doi.org/10.1016/j.stemcr.2014.08.009

40. Hen G, Nicenboim J, Mayseless O, Asaf L, Shin M, Busolin G, Hofi R, Almog G, Tiso N, Lawson ND, Yaniv K (2015) Venousderived angioblasts generate organ-specific vessels during zebrafish embryonic development. Development 142(24):42664278. https://doi.org/10.1242/dev.129247

41. Lancrin C, Sroczynska P, Stephenson C, Allen T, Kouskoff V, Lacaud G (2009) The haemangioblast generates haematopoietic cells through a haemogenic endothelium stage. Nature 457(7231):892-895. https://doi.org/10.1038/nature07679

42. Huber TL, Kouskoff V, Fehling HJ, Palis J, Keller G (2004) Haemangioblast commitment is initiated in the primitive streak of the mouse embryo. Nature 432(7017):625-630. https://doi.org/ 10.1038/nature03122

43. Pijuan-Sala B, Griffiths JA, Guibentif C, Hiscock TW, Jawaid W, Calero-Nieto FJ, Mulas C, Ibarra-Soria X, Tyser RCV, Ho DLL, Reik W, Srinivas S, Simons BD, Nichols J, Marioni JC, Gottgens B (2019) A single-cell molecular map of mouse gastrulation and early organogenesis. Nature 566(7745):490-495. https://doi.org/ 10.1038/s41586-019-0933-9

44. Scialdone A, Tanaka Y, Jawaid W, Moignard V, Wilson NK, Macaulay IC, Marioni JC, Gottgens B (2016) Resolving early mesoderm diversification through single-cell expression profiling. Nature 535(7611):289-293. https://doi.org/10.1038/natur e18633

45. Lee Y, Leslie J, Yang Y, Ding L (2021) Hepatic stellate and endothelial cells maintain hematopoietic stem cells in the developing liver. J Exp Med 218(3):e20200882. https://doi. org/10.1084/jem.20200882

46. Zovein AC, Hofmann JJ, Lynch M, French WJ, Turlo KA, Yang Y, Becker MS, Zanetta L, Dejana E, Gasson JC, Tallquist MD, Iruela-Arispe ML (2008) Fate tracing reveals the endothelial origin of hematopoietic stem cells. Cell Stem Cell 3(6):625636. https://doi.org/10.1016/j.stem.2008.09.018

47. Bailey AS, Willenbring H, Jiang S, Anderson DA, Schroeder DA, Wong MH, Grompe M, Fleming WH (2006) Myeloid lineage progenitors give rise to vascular endothelium. Proc Natl Acad Sci U S A 103(35):13156-13161. https://doi.org/ 10.1073/pnas.0604203103

48. Plein A, Fantin A, Denti L, Pollard JW, Ruhrberg C (2018) Erythro-myeloid progenitors contribute endothelial cells to blood vessels. Nature 562(7726):223-228. https://doi.org/10. 1038/s41586-018-0552-x

49. Feng T, Gao ZB, Kou S, Huang XY, Jiang Z, Lu ZK, Meng JF, Lin CP, Zhang H (2020) No evidence for erythro-myeloid progenitor-derived vascular endothelial cells in multiple organs. Circulation Research 127(10):1221-1232. https://doi.org/10. 1161/Circresaha.120.317442

50. Goldman O, Han S, Sourisseau M, Dziedzic N, Hamou W, Corneo B, D'Souza S, Sato T, Kotton DN, Bissig KD, Kalir T, Jacobs A, Evans T, Evans MJ, Gouon-Evans V (2013) KDR identifies a conserved human and murine hepatic progenitor and instructs early liver development. Cell Stem Cell 12(6):748-760. https://doi.org/10.1016/j.stem.2013.04.026

51. Arai T, Sakurai T, Kamiyoshi A, Ichikawa-Shindo Y, Inuma N, Iesato Y, Koyama T, Yoshizawa T, Uetake R, Yamauchi A, Yang L, Kawate H, Ogawa S, Kobayashi A, Miyagawa S, Shindo T (2011) Induction of LYVE-1/stabilin-2-positive liver sinusoidal endothelial-like cells from embryoid bodies by modulation of adrenomedullin-RAMP2 signaling. Peptides 32(9):1855-1865. https://doi.org/10.1016/j.peptides.2011.07. 005

52. Nonaka H, Watabe T, Saito S, Miyazono K, Miyajima A (2008) Development of stabilin2+ endothelial cells from mouse embryonic stem cells by inhibition of TGFbeta/activin signaling.
Biochem Biophys Res Commun 375(2):256-260. https://doi. org/10.1016/j.bbrc.2008.08.026

53. Koui Y, Kido T, Ito T, Oyama H, Chen SW, Katou Y, Shirahige K, Miyajima A (2017) An in vitro human liver model by iPSC-derived parenchymal and non-parenchymal cells. Stem Cell Reports 9(2):490-498. https://doi.org/10.1016/j.stemcr.2017.06. 010

54. Gage BK, Liu JC, Innes BT, MacParland SA, McGilvray ID, Bader GD, Keller GM (2020) Generation of functional liver sinusoidal endothelial cells from human pluripotent stem-cell-derived venous angioblasts. Cell Stem Cell 27(2):254-269. https://doi. org/10.1016/j.stem.2020.06.007

55. Singhal M, Liu X, Inverso D, Jiang K, Dai J, He H, Bartels S, Li W, Abdul Pari AA, Gengenbacher N, Besemfelder E, Hui L, Augustin HG, Hu J (2018) Endothelial cell fitness dictates the source of regenerating liver vasculature. J Exp Med 215(10):2497-2508. https://doi.org/10.1084/jem.20180008

56. Harb R, Xie G, Lutzko C, Guo Y, Wang X, Hill CK, Kanel GC, DeLeve LD (2009) Bone marrow progenitor cells repair rat hepatic sinusoidal endothelial cells after liver injury. Gastroenterology 137(2):704-712. https://doi.org/10.1053/j.gastro.2009. 05.009

57. Wang L, Wang X, Xie G, Wang L, Hill CK, DeLeve LD (2012) Liver sinusoidal endothelial cell progenitor cells promote liver regeneration in rats. J Clin Invest 122(4):1567-1573. https://doi. org/10.1172/JCI58789

58. Geraud C, Schledzewski K, Demory A, Klein D, Kaus M, Peyre F, Sticht C, Evdokimov K, Lu S, Schmieder A, Goerdt S (2010) Liver sinusoidal endothelium: a microenvironment-dependent differentiation program in rat including the novel junctional protein liver endothelial differentiation-associated protein-1. Hepatology 52(1):313-326. https://doi.org/10.1002/hep.23618

59. Olsavszky V, Ulbrich F, Singh S, Diett M, Sticht C, Schmid CD, Zierow J, Wohlfeil SA, Schledzewski K, Dooley S, Gaitantzi H, Breitkopf-Heinlein K, Geraud C, Goerdt S, Koch PS (2017) GATA4 and LMO3 balance angiocrine signaling and autocrine inflammatory activation by BMP2 in liver sinusoidal endothelial cells. Gene 627:491-499. https://doi.org/10.1016/j.gene.2017.06. 051

60. Wohlfeil SA, Hafele V, Dietsch B, Schledzewski K, Winkler M, Zierow J, Leibing T, Mohammadi MM, Heineke J, Sticht C, Olsavszky V, Koch PS, Geraud C, Goerdt S (2019) Hepatic endothelial Notch activation protects against liver metastasis by regulating endothelial-tumor cell adhesion independent of angiocrine signaling. Cancer Res 79(3):598-610. https://doi.org/10. 1158/0008-5472.CAN-18-1752

61. Winkler M, Staniczek T, Kurschner SW, Schmid CD, Schonhaber H, Cordero J, Kessler L, Mathes A, Sticht C, Nessling M, Uvarovskii A, Anders S, Zhang XJ, von Figura G, Hartmann D, Mogler C, Dobreva G, Schledzewski K, Geraud C, Koch PS, Goerdt S (2021) Endothelial GATA4 controls liver fibrosis and regeneration by preventing a pathogenic switch in angiocrine signaling. J Hepatol 74(2):380-393. https://doi.org/10.1016/j. jhep.2020.08.033

62. Kalucka J, de Rooij L, Goveia J, Rohlenova K, Dumas SJ, Meta E, Conchinha NV, Taverna F, Teuwen LA, Veys K, GarciaCaballero M, Khan S, Geldhof V, Sokol L, Chen R, Treps L, Borri M, de Zeeuw P, Dubois C, Karakach TK, Falkenberg KD, Parys M, Yin X, Vinckier S, Du Y, Fenton RA, Schoonjans L, Dewerchin M, Eelen G, Thienpont B, Lin L, Bolund L, Li X, Luo Y, Carmeliet P (2020) Single-cell transcriptome atlas of murine endothelial cells. Cell 180(4):764-779. https://doi.org/10.1016/j. cell.2020.01.015

63. de Haan W, Oie C, Benkheil M, Dheedene W, Vinckier S, Coppiello G, Aranguren XL, Beerens M, Jaekers J, Topal B, Verfaillie C, Smedsrod B, Luttun A (2020) Unraveling the 
transcriptional determinants of liver sinusoidal endothelial cell specialization. Am J Physiol Gastrointest Liver Physiol 318(4):G803-G815. https://doi.org/10.1152/ajpgi.00215.2019

64. Danoy M, Poulain S, Koui Y, Tauran Y, Scheidecker B, Kido T, Miyajima A, Sakai Y, Plessy C, Leclerc E (2020) Transcriptome profiling of hiPSC-derived LSECs with nanoCAGE. Mol Omics 16(2):138-146. https://doi.org/10.1039/c9mo00135b

65. Gracia-Sancho J, Marrone G, Fernandez-Iglesias A (2019) Hepatic microcirculation and mechanisms of portal hypertension. Nat Rev Gastroenterol Hepatol 16(4):221-234. https://doi. org/10.1038/s41575-018-0097-3

66. Parmar KM, Larman HB, Dai G, Zhang Y, Wang ET, Moorthy SN, Kratz JR, Lin Z, Jain MK, Gimbrone MA Jr, Garcia-Cardena $\mathrm{G}$ (2006) Integration of flow-dependent endothelial phenotypes by Kruppel-like factor 2. J Clin Invest 116(1):49-58. https://doi. org/10.1172/JCI24787

67. Lorenz L, Axnick J, Buschmann T, Henning C, Urner S, Fang S, Nurmi H, Eichhorst N, Holtmeier R, Bodis K, Hwang JH, Mussig K, Eberhard D, Stypmann J, Kuss O, Roden M, Alitalo K, Haussinger D, Lammert E (2018) Mechanosensing by beta1 integrin induces angiocrine signals for liver growth and survival. Nature 562(7725):128-132. https://doi.org/10.1038/s41586-018-0522-3

68. Maeso-Diaz R, Ortega-Ribera M, Fernandez-Iglesias A, Hide D, Munoz L, Hessheimer AJ, Vila S, Frances R, Fondevila C, Albillos A, Peralta C, Bosch J, Tacke F, Cogger VC, Gracia-Sancho $\mathrm{J}$ (2018) Effects of aging on liver microcirculatory function and sinusoidal phenotype. Aging Cell 17(6):e12829. https://doi.org/ 10.1111/acel.12829

69. Grosse L, Wagner N, Emelyanov A, Molina C, Lacas-Gervais S, Wagner KD, Bulavin DV (2020) Defined p16(high) senescent cell types are indispensable for mouse healthspan. Cell Metab 32(1):87-99. https://doi.org/10.1016/j.cmet.2020.05.002

70. Omori S, Wang TW, Johmura Y, Kanai T, Nakano Y, Kido T, Susaki EA, Nakajima T, Shichino S, Ueha S, Ozawa M, Yokote K, Kumamoto S, Nishiyama A, Sakamoto T, Yamaguchi K, Hatakeyama S, Shimizu E, Katayama K, Yamada Y, Yamazaki S, Iwasaki K, Miyoshi C, Funato H, Yanagisawa M, Ueno H, Imoto S, Furukawa Y, Yoshida N, Matsushima K, Ueda HR, Miyajima A, Nakanishi M (2020) Generation of a p16 reporter mouse and its use to characterize and target p16(high) cells in vivo. Cell Metab 32(5):814-828. https://doi.org/10.1016/j.cmet.2020.09. 006

71. Hilscher MB, Sehrawat T, Arab JP, Zeng Z, Gao J, Liu M, Kostallari E, Gao Y, Simonetto DA, Yaqoob U, Cao S, Revzin A, Beyder A, Wang RA, Kamath PS, Kubes P, Shah VH (2019) Mechanical stretch increases expression of CXCL1 in liver sinusoidal endothelial cells to recruit neutrophils, generate sinusoidal microthombi, and promote portal hypertension. Gastroenterology 157(1):193-209. https://doi.org/10.1053/j.gastro.2019.03.013

72. Peghaire C, Dufton NP, Lang M, Salles C II, Ahnstrom J, Kalna V, Raimondi C, Pericleous C, Inuabasi L, Kiseleva R, Muzykantov VR, Mason JC, Birdsey GM, Randi AM (2019) The transcription factor ERG regulates a low shear stress-induced anti-thrombotic pathway in the microvasculature. Nat Commun 10(1):5014. https://doi.org/10.1038/s41467-019-12897-w

73. Jackel S, Kiouptsi K, Lillich M, Hendrikx T, Khandagale A, Kollar B, Hormann N, Reiss C, Subramaniam S, Wilms E, Ebner K, Bruhl MV, Rausch P, Baines JF, Haberichter S, Lammle B, Binder CJ, Jurk K, Ruggeri ZM, Massberg S, Walter U, Ruf W, Reinhardt C (2017) Gut microbiota regulate hepatic von Willebrand factor synthesis and arterial thrombus formation via Tolllike receptor-2. Blood 130(4):542-553. https://doi.org/10.1182/ blood-2016-11-754416

74. Fraser R, Bosanquet AG, Day WA (1978) Filtration of chylomicrons by the liver may influence cholesterol metabolism and atherosclerosis. Atherosclerosis 29(2):113-123. https://doi.org/ 10.1016/0021-9150(78)90001-1

75. Herrnberger L, Hennig R, Kremer W, Hellerbrand C, Goepferich A, Kalbitzer HR, Tamm ER (2014) Formation of fenestrae in murine liver sinusoids depends on plasmalemma vesicle-associated protein and is required for lipoprotein passage. PLoS One 9(12):e115005. https://doi.org/10.1371/journal.pone.0115005

76. Kostallari E, Shah VH (2016) Angiocrine signaling in the hepatic sinusoids in health and disease. Am J Physiol Gastrointest Liver Physiol 311(2):G246-251. https://doi.org/10.1152/ajpgi.00118. 2016

77. Malovic I, Sorensen KK, Elvevold KH, Nedredal GI, Paulsen S, Erofeev AV, Smedsrod BH, McCourt PA (2007) The mannose receptor on murine liver sinusoidal endothelial cells is the main denatured collagen clearance receptor. Hepatology 45(6):14541461. https://doi.org/10.1002/hep.21639

78. Stegner D, Popp M, Lorenz V, Wax JK, Gessner JE, Nieswandt B (2016) FcgammaRIIB on liver sinusoidal endothelial cells is essential for antibody-induced GPVI ectodomain shedding in mice. Blood 128(6):862-865. https://doi.org/10.1182/ blood-2016-05-714378

79. Politz O, Gratchev A, McCourt PA, Schledzewski K, Guillot P, Johansson S, Svineng G, Franke P, Kannicht C, Kzhyshkowska J, Longati P, Velten FW, Johansson S, Goerdt S (2002) Stabilin-1 and -2 constitute a novel family of fasciclin-like hyaluronan receptor homologues. Biochem J 362(Pt 1):155-164. https://doi. org/10.1042/0264-6021:3620155

80. Elvevold K, Simon-Santamaria J, Hasvold H, McCourt P, Smedsrod B, Sorensen KK (2008) Liver sinusoidal endothelial cells depend on mannose receptor-mediated recruitment of lysosomal enzymes for normal degradation capacity. Hepatology 48(6):2007-2015. https://doi.org/10.1002/hep.22527

81. Ganesan LP, Kim J, Wu Y, Mohanty S, Phillips GS, Birmingham DJ, Robinson JM, Anderson CL (2012) FcgammaRIIb on liver sinusoidal endothelium clears small immune complexes. J Immunol 189(10):4981-4988. https://doi.org/10.4049/jimmunol. 1202017

82. Schledzewski K, Geraud C, Arnold B, Wang S, Grone HJ, Kempf T, Wollert KC, Straub BK, Schirmacher P, Demory A, Schonhaber H, Gratchev A, Dietz L, Thierse HJ, Kzhyshkowska J, Goerdt S (2011) Deficiency of liver sinusoidal scavenger receptors stabilin-1 and -2 in mice causes glomerulofibrotic nephropathy via impaired hepatic clearance of noxious blood factors. J Clin Invest 121(2):703-714. https://doi.org/10.1172/JCI44740

83. Shetty S, Lalor PF, Adams DH (2018) Liver sinusoidal endothelial cells - gatekeepers of hepatic immunity. Nat Rev Gastroenterol Hepatol 15(9):555-567. https://doi.org/10.1038/ s41575-018-0020-y

84. Lin G, Simmons G, Pohlmann S, Baribaud F, Ni H, Leslie GJ, Haggarty BS, Bates P, Weissman D, Hoxie JA, Doms RW (2003) Differential N-linked glycosylation of human immunodeficiency virus and Ebola virus envelope glycoproteins modulates interactions with DC-SIGN and DC-SIGNR. J Virol 77(2):1337-1346. https://doi.org/10.1128/jvi.77.2.1337-1346.2003

85. Marzi A, Gramberg T, Simmons G, Moller P, Rennekamp AJ, Krumbiegel M, Geier M, Eisemann J, Turza N, Saunier B, Steinkasserer A, Becker S, Bates P, Hofmann H, Pohlmann S (2004) DC-SIGN and DC-SIGNR interact with the glycoprotein of Marburg virus and the S protein of severe acute respiratory syndrome coronavirus. J Virol 78(21):12090-12095. https://doi. org/10.1128/JVI.78.21.12090-12095.2004

86. Simon-Santamaria J, Rinaldo CH, Kardas P, Li R, Malovic I, Elvevold K, McCourt P, Smedsrod B, Hirsch HH, Sorensen KK (2014) Efficient uptake of blood-borne BK and JC polyomaviruslike particles in endothelial cells of liver sinusoids and renal vasa 
recta. PLoS One 9(11):e111762. https://doi.org/10.1371/journal. pone. 0111762

87. Ganesan LP, Mohanty S, Kim J, Clark KR, Robinson JM, Anderson CL (2011) Rapid and efficient clearance of blood-borne virus by liver sinusoidal endothelium. PLoS Pathog 7(9):e1002281. https://doi.org/10.1371/journal.ppat.1002281

88. Klenerman P, Ramamurthy N (2015) Liver sinusoidal endothelial cells: an antiviral "defendothelium." Gastroenterology 148(2):288-291. https://doi.org/10.1053/j.gastro.2014.12.010

89. Bleau C, Filliol A, Samson M, Lamontagne L (2016) Mouse hepatitis virus infection induces a Toll-like receptor 2-dependent activation of inflammatory functions in liver sinusoidal endothelial cells during acute hepatitis. J Virol 90(20):9096-9113. https://doi.org/10.1128/JVI.01069-16

90. Neumann K, Rudolph C, Neumann C, Janke M, Amsen D, Scheffold A (2015) Liver sinusoidal endothelial cells induce immunosuppressive IL-10-producing Th1 cells via the Notch pathway. Eur J Immunol 45(7):2008-2016. https://doi.org/10.1002/eji. 201445346

91. Carambia A, Freund B, Schwinge D, Bruns OT, Salmen SC, Ittrich H, Reimer R, Heine M, Huber S, Waurisch C, Eychmuller A, Wraith DC, Korn T, Nielsen P, Weller H, Schramm C, Luth S, Lohse AW, Heeren J, Herkel J (2015) Nanoparticle-based autoantigen delivery to Treg-inducing liver sinusoidal endothelial cells enables control of autoimmunity in mice. J Hepatol 62(6):1349-1356. https://doi.org/10.1016/j.jhep.2015.01.006

92. Wittlich M, Dudek M, Bottcher JP, Schanz O, Hegenbarth S, Bopp T, Schmitt E, Kurts C, Garbers C, Rose John S, Knolle PA, Wohlleber D (2017) Liver sinusoidal endothelial cell crosspriming is supported by CD4 T cell-derived IL-2. J Hepatol 66(5):978-986. https://doi.org/10.1016/j.jhep.2016.12.015

93. Limmer A, Ohl J, Kurts C, Ljunggren HG, Reiss Y, Groettrup M, Momburg F, Arnold B, Knolle PA (2000) Efficient presentation of exogenous antigen by liver endothelial cells to CD8+ T cells results in antigen-specific T-cell tolerance. Nat Med 6(12):13481354. https://doi.org/10.1038/82161

94. Burgdorf S, Kautz A, Bohnert V, Knolle PA, Kurts C (2007) Distinct pathways of antigen uptake and intracellular routing in CD4 and CD8 T cell activation. Science 316(5824):612-616. https://doi.org/10.1126/science.1137971

95. Schurich A, Berg M, Stabenow D, Bottcher J, Kern M, Schild HJ, Kurts C, Schuette V, Burgdorf S, Diehl L, Limmer A, Knolle PA (2010) Dynamic regulation of CD8 T cell tolerance induction by liver sinusoidal endothelial cells. J Immunol 184(8):4107-4114. https://doi.org/10.4049/jimmunol.0902580

96. Shetty S, Weston CJ, Oo YH, Westerlund N, Stamataki Z, Youster J, Hubscher SG, Salmi M, Jalkanen S, Lalor PF, Adams DH (2011) Common lymphatic endothelial and vascular endothelial receptor-1 mediates the transmigration of regulatory $\mathrm{T}$ cells across human hepatic sinusoidal endothelium. J Immunol 186(7):4147-4155. https://doi.org/10.4049/jimmunol.1002961

97. Patten DA, Wilson GK, Bailey D, Shaw RK, Jalkanen S, Salmi M, Rot A, Weston CJ, Adams DH, Shetty S (2017) Human liver sinusoidal endothelial cells promote intracellular crawling of lymphocytes during recruitment: a new step in migration. Hepatology 65(1):294-309. https://doi.org/10.1002/hep.28879

98. Guidotti LG, Inverso D, Sironi L, Di Lucia P, Fioravanti J, Ganzer L, Fiocchi A, Vacca M, Aiolfi R, Sammicheli S, Mainetti M, Cataudella T, Raimondi A, Gonzalez-Aseguinolaza G, Protzer U, Ruggeri ZM, Chisari FV, Isogawa M, Sitia G, Iannacone M (2015) Immunosurveillance of the liver by intravascular effector CD8(+) T cells. Cell 161(3):486-500. https://doi.org/10.1016/j. cell.2015.03.005

99. Braet F, Wisse E (2002) Structural and functional aspects of liver sinusoidal endothelial cell fenestrae: a review. Comp Hepatol 1(1):1. https://doi.org/10.1186/1476-5926-1-1
100. Soto-Gutierrez A, Gough A, Vernetti LA, Taylor DL, Monga SP (2017) Pre-clinical and clinical investigations of metabolic zonation in liver diseases: the potential of microphysiology systems. Exp Biol Med (Maywood) 242(16):1605-1616. https://doi.org/ $10.1177 / 1535370217707731$

101. Benhamouche S, Decaens T, Godard C, Chambrey R, Rickman DS, Moinard C, Vasseur-Cognet M, Kuo CJ, Kahn A, Perret C, Colnot S (2006) Apc tumor suppressor gene is the "zonationkeeper" of mouse liver. Dev Cell 10(6):759-770. https://doi.org/ 10.1016/j.devcel.2006.03.015

102. Abraham M, Augustine D, Rao RS, Sowmya SV, Haragannavar VC, Nambiar S, Prasad K, Awan KH, Patil S (2017) Naturally available extracts inhibiting cancer progression: a systematic review. J Evid Based Complementary Altern Med 22(4):870 878. https://doi.org/10.1177/2156587217744914

103. Behari J, Yeh TH, Krauland L, Otruba W, Cieply B, Hauth B, Apte U, Wu T, Evans R, Monga SP (2010) Liver-specific betacatenin knockout mice exhibit defective bile acid and cholesterol homeostasis and increased susceptibility to diet-induced steatohepatitis. Am J Pathol 176(2):744-753. https://doi.org/10.2353/ ajpath.2010.090667

104. Liu S, Yeh TH, Singh VP, Shiva S, Krauland L, Li H, Zhang P, Kharbanda K, Ritov V, Monga SP, Scott DK, Eagon PK, Behari $\mathbf{J}$ (2012) beta-catenin is essential for ethanol metabolism and protection against alcohol-mediated liver steatosis in mice. Hepatology 55(3):931-940. https://doi.org/10.1002/hep.24766

105. Yang J, Mowry LE, Nejak-Bowen KN, Okabe H, Diegel CR, Lang RA, Williams BO, Monga SP (2014) beta-catenin signaling in murine liver zonation and regeneration: a Wnt-Wnt situation! Hepatology 60(3):964-976. https://doi.org/10.1002/hep.27082

106. Liu H, Fergusson MM, Wu JJ, Rovira II, Liu J, Gavrilova O, Lu T, Bao J, Han D, Sack MN, Finkel T (2011) Wnt signaling regulates hepatic metabolism. Sci Signal 4(158):ra6. https://doi. org/10.1126/scisignal.2001249

107. Ding BS, Nolan DJ, Butler JM, James D, Babazadeh AO, Rosenwaks Z, Mittal V, Kobayashi H, Shido K, Lyden D, Sato TN, Rabbany SY, Rafii S (2010) Inductive angiocrine signals from sinusoidal endothelium are required for liver regeneration. Nature 468(7321):310-315. https://doi.org/10.1038/nature09493

108. Zhang XJ, Olsavszky V, Yin Y, Wang B, Engleitner T, Ollinger R, Schledzewski K, Koch PS, Rad R, Schmid RM, Friess H, Goerdt S, Huser N, Geraud C, von Figura G, Hartmann D (2020) Angiocrine hepatocyte growth factor signaling controls physiological organ and body size and dynamic hepatocyte proliferation to prevent liver damage during regeneration. Am J Pathol 190(2):358-371. https://doi.org/10.1016/j.ajpath.2019.10.009

109. Hu J, Srivastava K, Wieland M, Runge A, Mogler C, Besemfelder E, Terhardt D, Vogel MJ, Cao L, Korn C, Bartels S, Thomas M, Augustin HG (2014) Endothelial cell-derived angiopoietin-2 controls liver regeneration as a spatiotemporal rheostat. Science 343(6169):416-419. https://doi.org/10.1126/science.1244880

110. Ding BS, Cao Z, Lis R, Nolan DJ, Guo P, Simons M, Penfold ME, Shido K, Rabbany SY, Rafii S (2014) Divergent angiocrine signals from vascular niche balance liver regeneration and fibrosis. Nature 505(7481):97-102. https://doi.org/10.1038/natur e12681

111. Shido K, Chavez D, Cao Z, Ko JL, Rafii S, Ding B-S (2017) Platelets prime hematopoietic-vascular niche to drive angiocrine-mediated liver regeneration. Signal Transduction and Targeted Therapy 2(1):16044. https://doi.org/10.1038/sigtrans.2016. 44

112. Chembazhi UV, Bangru S, Hernaez M, Kalsotra A (2021) Cellular plasticity balances the metabolic and proliferation dynamics of a regenerating liver. Genome Res. https://doi.org/10.1101/gr. 267013.120 
113. Manavski Y, Abel T, Hu J, Kleinlutzum D, Buchholz CJ, Belz C, Augustin HG, Boon RA, Dimmeler S (2017) Endothelial transcription factor KLF2 negatively regulates liver regeneration via induction of activin A. Proc Natl Acad Sci USA 114(15):39933998. https://doi.org/10.1073/pnas.1613392114

114. Schaffner F, Poper H (1963) Capillarization of hepatic sinusoids in man. Gastroenterology 44:239-242

115. Le Couteur DG, Fraser R, Cogger VC, McLean AJ (2002) Hepatic pseudocapillarisation and atherosclerosis in ageing. Lancet 359(9317):1612-1615. https://doi.org/10.1016/S01406736(02)08524-0

116. Xie G, Wang X, Wang L, Wang L, Atkinson RD, Kanel GC, Gaarde WA, Deleve LD (2012) Role of differentiation of liver sinusoidal endothelial cells in progression and regression of hepatic fibrosis in rats. Gastroenterology 142(4):918-927e916. https://doi.org/10.1053/j.gastro.2011.12.017

117. Duan JL, Ruan B, Yan XC, Liang L, Song P, Yang ZY, Liu Y, Dou KF, Han H, Wang L (2018) Endothelial Notch activation reshapes the angiocrine of sinusoidal endothelia to aggravate liver fibrosis and blunt regeneration in mice. Hepatology 68(2):677-690. https://doi.org/10.1002/hep.29834

118. Desroches-Castan A, Tillet E, Ricard N, Ouarne M, Mallet C, Belmudes L, Coute Y, Boillot O, Scoazec JY, Bailly S, Feige JJ (2019) Bone morphogenetic protein 9 is a paracrine factor controlling liver sinusoidal endothelial cell fenestration and protecting against hepatic fibrosis. Hepatology 70(4):1392-1408. https://doi.org/10.1002/hep.30655

119. Xie G, Choi SS, Syn WK, Michelotti GA, Swiderska M, Karaca G, Chan IS, Chen Y, Diehl AM (2013) Hedgehog signalling regulates liver sinusoidal endothelial cell capillarisation. Gut 62(2):299-309. https://doi.org/10.1136/gutjnl-2011-301494

120. Xing Y, Zhao T, Gao X, Wu Y (2016) Liver X receptor alpha is essential for the capillarization of liver sinusoidal endothelial cells in liver injury. Sci Rep 6:21309. https://doi.org/10.1038/ srep21309

121. Raines SM, Richards OC, Schneider LR, Schueler KL, Rabaglia ME, Oler AT, Stapleton DS, Genove G, Dawson JA, Betsholtz C, Attie AD (2011) Loss of PDGF-B activity increases hepatic vascular permeability and enhances insulin sensitivity. Am J Physiol Endocrinol Metab 301(3):E517-526. https://doi. org/10.1152/ajpendo.00241.2011

122. Ding BS, Liu CH, Sun Y, Chen Y, Swendeman SL, Jung B, Chavez D, Cao Z, Christoffersen C, Nielsen LB, Schwab SR, Rafii S, Hla T (2016) HDL activation of endothelial sphingosine-1-phosphate receptor-1 (S1P1) promotes regeneration and suppresses fibrosis in the liver. JCI Insight 1(21):e87058. https://doi.org/10.1172/jci.insight. 87058

123. Dufton NP, Peghaire CR, Osuna-Almagro L, Raimondi C, Kalna V, Chauhan A, Webb G, Yang Y, Birdsey GM, Lalor P, Mason JC, Adams DH, Randi AM (2017) Dynamic regulation of canonical TGFbeta signalling by endothelial transcription factor ERG protects from liver fibrogenesis. Nat Commun 8(1):895. https://doi.org/10.1038/s41467-017-01169-0

124. Cao Z, Ye T, Sun Y, Ji G, Shido K, Chen Y, Luo L, Na F, Li X, Huang Z, Ko JL, Mittal V, Qiao L, Chen C, Martinez FJ, Rafii S, Ding BS (2017) Targeting the vascular and perivascular niches as a regenerative therapy for lung and liver fibrosis. Sci Transl Med. https://doi.org/10.1126/scitranslmed.aai8710

125. Delire B, Starkel P, Leclercq I (2015) Animal models for fibrotic liver diseases: what we have, what we need, and what Is under development. J Clin Transl Hepatol 3(1):53-66. https://doi.org/10.14218/JCTH.2014.00035

126. Xu M, Xu HH, Lin Y, Sun X, Wang LJ, Fang ZP, Su XH, Liang XJ, Hu Y, Liu ZM, Cheng Y, Wei Y, Li J, Li L, Liu HJ, Cheng Z, Tang N, Peng C, Li T, Liu T, Qiao L, Wu D, Ding YQ, Zhou WJ (2019) LECT2, a ligand for Tie1, plays a crucial role in liver fibrogenesis. Cell 178(6):1478-1492 e1420. https://doi. org/10.1016/j.cell.2019.07.021

127. Higashi T, Friedman SL, Hoshida Y (2017) Hepatic stellate cells as key target in liver fibrosis. Adv Drug Deliv Rev 121:27-42. https://doi.org/10.1016/j.addr.2017.05.007

128. Hammad S, Braeuning A, Meyer C, Mohamed F, Hengstler JG, Dooley S (2017) A frequent misinterpretation in current research on liver fibrosis: the vessel in the center of CCl4-induced pseudolobules is a portal vein. Arch Toxicol 91(11):3689-3692. https://doi.org/10.1007/s00204-017-2040-8

129. Li Z, Chen B, Dong W, Kong M, Shao Y, Fan Z, Yu L, Wu D, Lu J, Guo J, Xu Y (2019) The chromatin remodeler Brg1 integrates ROS production and endothelial-mesenchymal transition to promote liver fibrosis in mice. Front Cell Dev Biol 7:245. https://doi.org/10.3389/fcell.2019.00245

130. Gao J, Wei B, Liu M, Hirsova P, Sehrawat TS, Cao S, Hu X, Xue F, Yaqoob U, Kang N, Cui H, Pomerantz WCK, Kostallari E, Shah VH (2020) Endothelial p300 promotes portal hypertension and hepatic fibrosis through CCL2-mediated angiocrine signaling. Hepatology. https://doi.org/10.1002/hep.31617

131. Maretti-Mira AC, Wang X, Wang L, DeLeve LD (2019) Incomplete differentiation of engrafted bone marrow endothelial progenitor cells initiates hepatic fibrosis in the rat. Hepatology 69(3):1259-1272. https://doi.org/10.1002/hep.30227

132. Huang G, Besner GE, Brigstock DR (2012) Heparin-binding epidermal growth factor-like growth factor suppresses experimental liver fibrosis in mice. Lab Invest 92(5):703-712. https:// doi.org/10.1038/labinvest.2012.3

133. Takemura T, Yoshida Y, Kiso S, Kizu T, Furuta K, Ezaki H, Hamano M, Egawa M, Chatani N, Kamada Y, Imai Y, Higashiyama S, Iwamoto R, Mekada E, Takehara T (2013) Conditional loss of heparin-binding EGF-like growth factor results in enhanced liver fibrosis after bile duct ligation in mice. Biochem Biophys Res Commun 437(2):185-191. https://doi.org/10.1016/j. bbrc.2013.05.097

134. Ruart M, Chavarria L, Camprecios G, Suarez-Herrera N, Montironi C, Guixe-Muntet S, Bosch J, Friedman SL, Garcia-Pagan JC, Hernandez-Gea V (2019) Impaired endothelial autophagy promotes liver fibrosis by aggravating the oxidative stress response during acute liver injury. J Hepatol 70(3):458-469. https://doi. org/10.1016/j.jhep.2018.10.015

135. Hammoutene A, Biquard L, Lasselin J, Kheloufi M, Tanguy M, Vion AC, Merian J, Colnot N, Loyer X, Tedgui A, Codogno P, Lotersztajn S, Paradis V, Boulanger CM, Rautou PE (2020) A defect in endothelial autophagy occurs in patients with nonalcoholic steatohepatitis and promotes inflammation and fibrosis. J Hepatol 72(3):528-538. https://doi.org/10.1016/j.jhep.2019.10. 028

136. Tilg H, Moschen AR (2010) Evolution of inflammation in nonalcoholic fatty liver disease: the multiple parallel hits hypothesis. Hepatology 52(5):1836-1846. https://doi.org/10.1002/hep.24001

137. Hammoutene A, Rautou PE (2019) Role of liver sinusoidal endothelial cells in non-alcoholic fatty liver disease. J Hepatol 70(6):1278-1291. https://doi.org/10.1016/j.jhep.2019.02.012

138. Miyao M, Kotani H, Ishida T, Kawai C, Manabe S, Abiru H, Tamaki K (2015) Pivotal role of liver sinusoidal endothelial cells in NAFLD/NASH progression. Lab Invest 95(10):1130-1144. https://doi.org/10.1038/labinvest.2015.95

139. Xiong X, Kuang H, Ansari S, Liu T, Gong J, Wang S, Zhao XY, Ji Y, Li C, Guo L, Zhou L, Chen Z, Leon-Mimila P, Chung MT, Kurabayashi K, Opp J, Campos-Perez F, Villamil-Ramirez H, Canizales-Quinteros S, Lyons R, Lumeng CN, Zhou B, Qi L, Huertas-Vazquez A, Lusis AJ, Xu XZS, Li S, Yu Y, Li JZ, Lin JD (2019) Landscape of intercellular crosstalk in healthy and NASH liver revealed by single-cell secretome gene analysis. Mol Cell 
75(3):644-660 e645. https://doi.org/10.1016/j.molcel.2019.07. 028

140. Ramachandran P, Dobie R, Wilson-Kanamori JR, Dora EF, Henderson BEP, Luu NT, Portman JR, Matchett KP, Brice M, Marwick JA, Taylor RS, Efremova M, Vento-Tormo R, Carragher NO, Kendall TJ, Fallowfield JA, Harrison EM, Mole DJ, Wigmore SJ, Newsome PN, Weston CJ, Iredale JP, Tacke F, Pollard JW, Ponting CP, Marioni JC, Teichmann SA, Henderson NC (2019) Resolving the fibrotic niche of human liver cirrhosis at single-cell level. Nature 575(7783):512-518. https://doi.org/10. 1038/s41586-019-1631-3

141. Terkelsen MK, Bendixen SM, Hansen D, Scott EAH, Moeller AF, Nielsen R, Mandrup S, Schlosser A, Andersen TL, Sorensen GL, Krag A, Natarajan KN, Detlefsen S, Dimke H, Ravnskjaer K (2020) Transcriptional dynamics of hepatic sinusoid-associated cells after liver injury. Hepatology 72(6):2119-2133. https://doi. org/10.1002/hep.31215

142. Su T, Yang Y, Lai S, Jeong J, Jung Y, McConnell M, Utsumi T, Iwakiri Y (2020) Single-cell transcriptomics reveals zone-specific alterations of liver sinusoidal endothelial cells in cirrhosis. Cell Mol Gastroenterol Hepatol 11(4):1139-1161. https://doi. org/10.1016/j.jcmgh.2020.12.007

143. Geraud C, Mogler C, Runge A, Evdokimov K, Lu S, Schledzewski K, Arnold B, Hammerling G, Koch PS, Breuhahn K, Longerich T, Marx A, Weiss C, Damm F, Schmieder A, Schirmacher P, Augustin HG, Goerdt S (2013) Endothelial transdifferentiation in hepatocellular carcinoma: Loss of Stabilin-2 expression in peri-tumourous liver correlates with increased survival. Liver Int 33(9):1428-1440. https://doi.org/10.1111/liv.12262

144. Schmid CD, Schledzewski K, Mogler C, Waldburger N, Kalna V, Marx A, Randi AM, Geraud C, Goerdt S, Koch PS (2018) GPR182 is a novel marker for sinusoidal endothelial differentiation with distinct GPCR signaling activity in vitro. Biochem Biophys Res Commun 497(1):32-38. https://doi.org/10.1016/j. bbrc.2018.01.185

145. Zhao Q, Molina-Portela MDP, Parveen A, Adler A, Adler C, Hock E, Wang W, Ni M, Wei Y, Atwal G, Mohrs M, Thurston G, Eichten A (2020) Heterogeneity and chimerism of endothelial cells revealed by single-cell transcriptome in orthotopic liver tumors. Angiogenesis 23(4):581-597. https://doi.org/10.1007/ s10456-020-09727-9

146. Sharma A, Seow JJW, Dutertre CA, Pai R, Bleriot C, Mishra A, Wong RMM, Singh GSN, Sudhagar S, Khalilnezhad S, Erdal S, Teo HM, Khalilnezhad A, Chakarov S, Lim TKH, Fui ACY, Chieh AKW, Chung CP, Bonney GK, Goh BK, Chan JKY, Chow PKH, Ginhoux F, Das Gupta R (2020) Onco-fetal reprogramming of endothelial cells drives immunosuppressive macrophages in hepatocellular carcinoma. Cell 183(2):377-394. https://doi.org/ 10.1016/j.cell.2020.08.040

147. Chen L, Gu T, Li B, Li F, Ma Z, Zhang Q, Cai X (1866) Lu L (2019) Delta-like ligand 4/DLL4 regulates the capillarization of liver sinusoidal endothelial cell and liver fibrogenesis. Biochim Biophys Acta Mol Cell Res 10:1663-1675. https://doi.org/10. 1016/j.bbamcr.2019.06.011

148. Cuervo H, Nielsen CM, Simonetto DA, Ferrell L, Shah VH, Wang RA (2016) Endothelial notch signaling is essential to prevent hepatic vascular malformations in mice. Hepatology 64(4):1302-1316. https://doi.org/10.1002/hep.28713

149. Wang X, Wu X, Zhang A, Wang S, Hu C, Chen W, Shen Y, Tan R, Sun Y, Xu Q (2016) Targeting the PDGF-B/PDGFRbeta interface with Destruxin A5 to selectively block PDGF-BB/
PDGFR-betabeta signaling and attenuate liver fibrosis. EBioMedicine 7:146-156. https://doi.org/10.1016/j.ebiom.2016.03. 042

150. Yoshida S, Ikenaga N, Liu SB, Peng ZW, Chung J, Sverdlov DY, Miyamoto M, Kim YO, Ogawa S, Arch RH, Schuppan D, Popov Y (2014) Extrahepatic platelet-derived growth factor-beta, delivered by platelets, promotes activation of hepatic stellate cells and biliary fibrosis in mice. Gastroenterology 147(6):1378-1392. https://doi.org/10.1053/j.gastro.2014.08.038

151. Itkin T, Gur-Cohen S, Spencer JA, Schajnovitz A, Ramasamy SK, Kusumbe AP, Ledergor G, Jung Y, Milo I, Poulos MG, Kalinkovich A, Ludin A, Kollet O, Shakhar G, Butler JM, Rafii S, Adams RH, Scadden DT, Lin CP, Lapidot T (2016) Distinct bone marrow blood vessels differentially regulate haematopoiesis. Nature 532(7599):323-328. https://doi.org/10.1038/nature17624

152. Kusumbe AP, Adams RH (2014) Osteoclast progenitors promote bone vascularization and osteogenesis. Nat Med 20(11):12381240. https://doi.org/10.1038/nm.3747

153. Kusumbe AP, Ramasamy SK, Itkin T, Mae MA, Langen UH, Betsholtz C, Lapidot T, Adams RH (2016) Age-dependent modulation of vascular niches for haematopoietic stem cells. Nature 532(7599):380-384. https://doi.org/10.1038/nature17638

154. Ramasamy SK, Kusumbe AP, Wang L, Adams RH (2014) Endothelial Notch activity promotes angiogenesis and osteogenesis in bone. Nature 507(7492):376-380. https://doi.org/10. 1038/nature 13146

155. Shen B, Tasdogan A, Ubellacker JM, Zhang J, Nosyreva ED, Du L, Murphy MM, Hu S, Yi Y, Kara N, Liu X, Guela S, Jia Y, Ramesh V, Embree C, Mitchell EC, Zhao YC, Ju LA, Hu Z, Crane GM, Zhao Z, Syeda R, Morrison SJ (2021) A mechanosensitive peri-arteriolar niche for osteogenesis and lymphopoiesis. Nature. https://doi.org/10.1038/s41586-021-03298-5

156. Banerjee D, Hernandez SL, Garcia A, Kangsamaksin T, Sbiroli E, Andrews J, Forrester LA, Wei N, Kadenhe-Chiweshe A, Shawber CJ, Kitajewski JK, Kandel JJ, Yamashiro DJ (2015) Notch suppresses angiogenesis and progression of hepatic metastases. Cancer Res 75(8):1592-1602. https://doi.org/10.1158/ 0008-5472.CAN-14-1493

157. Wieland E, Rodriguez-Vita J, Liebler SS, Mogler C, Moll I, Herberich SE, Espinet E, Herpel E, Menuchin A, Chang-Claude J, Hoffmeister M, Gebhardt C, Brenner H, Trumpp A, Siebel CW, Hecker M, Utikal J, Sprinzak D, Fischer A (2017) Endothelial Notch1 activity facilitates metastasis. Cancer Cell 31(3):355367. https://doi.org/10.1016/j.ccell.2017.01.007

158. Yu X, Chen L, Liu J, Dai B, Xu G, Shen G, Luo Q, Zhang Z (2019) Immune modulation of liver sinusoidal endothelial cells by melittin nanoparticles suppresses liver metastasis. Nat Commun 10(1):574. https://doi.org/10.1038/s41467-019-08538-x

159. Finn RS, Qin S, Ikeda M, Galle PR, Ducreux M, Kim TY, Kudo M, Breder V, Merle P, Kaseb AO, Li D, Verret W, Xu DZ, Hernandez S, Liu J, Huang C, Mulla S, Wang Y, Lim HY, Zhu AX, Cheng AL, Investigators IM (2020) Atezolizumab plus Bevacizumab in unresectable hepatocellular carcinoma. N Engl J Med 382(20):1894-1905. https://doi.org/10.1056/NEJMoa1915745

Publisher's Note Springer Nature remains neutral with regard to jurisdictional claims in published maps and institutional affiliations. 